\title{
Conversion of Lignocellulosic Biomass to Bioethanol: An Overview with a Focus on Pretreatment
}

\author{
Yengkhom Disco Singh ${ }^{1^{*}}$, Kunja Bihari Satapathy ${ }^{1}$ \\ ${ }^{1}$ Department of Botany, School of Applied Sciences, Centurion University of Technology and \\ Management, Jatni, Bhubaneswar, Odisha-752050, India \\ *disco.iitg@gmail.com, disco.singh@cutm.ac.in
}

\begin{abstract}
Keywords: Lignocellulosic biomass, Pretreatment, Enzymatic saccharification, Cellulose, Hemicellulose, Lignin, biochemical conversion
\end{abstract}

\begin{abstract}
The present review article aims to highlight various pretreatment technologies involved in the biochemical conversion of biomass to bioethanol from lignocellulosic biomass without the process modification. Pretreatment technologies are aimed to increase the enzyme susceptibility to the biomass for high yield of ethanol production through microbial fermentation. Broadly, pretreatment methods are divided into four categories including physical, chemical, physicochemical and biological. This paper comprehensively reviewed on the lignocellulosic biomass to bioethanol process with focuses on pretreatment methods, their mechanisms, combination of different pretreatment technologies, the addition of external chemical agents, advantages, and disadvantages. It also discussed the ethanol productions from biomass in details without disturbing the process integrity.
\end{abstract}

\section{Introduction}

The world is facing serious energy problem due to depletion of fossil fuels. At the same time, the demand and need for energy in the transport sector have risen vigorously. One viable solution to this problem is making used out of alternate and renewable resources. Many countries have implemented policies for bioethanol production in other to replace the petrol-based engines. In this review, an attempt is made to understand the overview of research activities in the area of bioethanol production from lignocellulosic biomass. The review focused on the different pretreatment technologies that are involved in the synthesis of bioethanol.

According to the International Energy Agency (IEA), the global demand for biofuel would rise significantly by 2050 . The increasing global warming and its impact on the environment due to $\mathrm{CO}_{2}$ emission can be minimized by using the biofuel and bioenergy [1]. One of the most promising biofuels that we have is ethanol produced from lignocellulosic biomass by microbial fermentation. Lignocellulosic biomass (LCB) such as crop residues, grasses, sawdust, wood chip [180], oil palm, fruit bunch, trunk etc. are the potential feedstock for production of bioethanol [2, 178].These raw materials are easily available in local areas throughout the world. It is rather to say that ethanol production would be a more rural-friendly occupation.

Biomass energy or 'Bioenergy' is one of the most challenging renewable energy in modern fuels. The challenge is to ensure that biomass energy is produced in large scale and compensate the increased price of food. In other words, bioenergy should do a better job than fossil fuels in terms of its production, efficiency, and availability. Modern bioenergy resources include liquid biofuels, biomass-fired electricity, or methane from animal wastes. It also includes cellulosic ethanol and Fischer-Tropsch fuels [3].

Bioethanol is a clean and renewable fuel $[4,179]$. It is one of the most important products of industrial biotechnology. The main raw materials used for the production of ethanol in industry scale are sugar-based such as sugarcane, molasses, and starch-based materials such as wheat and corn. Based on such raw material, bioethanol may be divided into first, second and thirdgeneration [5]. The second generation of biofuel is more promising in terms of efficiency and low cost of raw material as compared to the first and third generation of biofuel. The second generation of biofuel is mainly depended on the lignocellulosic biomass. It seems that those 
countries, which have a significant agronomic-based economy or agricultural work for their livelihood, have greater advantages to incorporate currently available technology for fuel ethanol production. Bioethanol production will not be signed without proper improvement in the process as well as lowering energy consumption. During the last two decades, technology for bioethanol production from different feedstock has been developing in much higher and large-scale production became reality.

This paper comprehensively reviewed on the lignocellulosic biomass to bioethanol process with focuses on pretreatment methods, their mechanisms, combination of different pretreatment technologies, the addition of external chemical agents, advantages, and disadvantages. It also discussed the ethanol productions from biomass in details without disturbing the process integrity. It is very essential to highlight the different pretreatment methods as all the methods are equally important and it is not possible to have common methods for different types of biomass. It is because, biomass possess different types of composition and varies according to the type of the biomass.

\section{Composition of lignocellulosic biomass (LCB)}

Lignocellulose is the most abundant renewable biomass with a worldwide annual production of 1x1010 MT [6]. The term "Lignocellulosic biomass' is used when referring to higher plants such as hardwood or softwood. The main components of LCB are cellulose, hemicelluloses, lignin and inorganic materials [7]. Cellulose is the main component in lignocellulosic material followed by hemicelluloses then lignin. Cellulose and hemicelluloses are polysaccharides which are tightly bound to lignin by covalent cross-linkages or non-covalent forces [8] whereas, lignin is an aromatic polymer made up of phenylpropanoid precursors. Apart from the three basic chemical compounds (cellulose, hemicellulose, and lignin), lignocellulosic biomass content water, proteins, minerals and other compounds.

The organic component of biomass plays a major role in processing and producing biofuels. Cellulose is a major structural component of cell walls. It provides mechanical strength and contributes major fuel. The solar energy is absorbed through the process of photosynthesis and stored the energy as cellulose or hemicellulose [9]. It has been estimated that around $7.5 \times 10^{10}$ tonnes of cellulose are consumed and regenerated every year [10]. This is the main reasons why cellulose is considered as the most abundant organic compound on the Earth. The composition and proportion of these compounds vary from species to species depending upon plant cell wall structure [11-12]. Table 1 summarized the composition of the lignocellulosic biomass of different sources. 
Table 1. Percent composition of lignocellulosic biomass from several sources

\begin{tabular}{|c|c|c|c|c|}
\hline Lignocellulosic materials & $\begin{array}{c}\text { Cellulose } \\
(\%)\end{array}$ & $\begin{array}{c}\text { Hemicellulose } \\
(\%)\end{array}$ & Lignin (\%) & References \\
\hline Hardwoods stems & $240-55$ & $24-40$ & $18-25$ & \multirow{12}{*}{ [13] } \\
\hline Softwood stems & $45-50$ & $25-35$ & $25-35$ & \\
\hline Nut shells & $25-30$ & $25-30$ & $30-40$ & \\
\hline Corn cobs & 45 & 35 & 15 & \\
\hline Grasses & $25-40$ & $35-50$ & $10-30$ & \\
\hline Paper & $85-99$ & 0 & $0-15$ & \\
\hline Wheat straw & 30 & 50 & 15 & \\
\hline Sorted refuse & 60 & 20 & 20 & \\
\hline Leaves & $15-20$ & $80-85$ & 0 & \\
\hline Cotton seed hairs & $80-95$ & $5-20$ & 0 & \\
\hline Newspaper & $40-55$ & $25-40$ & $18-30$ & \\
\hline $\begin{array}{l}\text { Waste papers from } \\
\text { chemical pulps }\end{array}$ & $60-70$ & $10-20$ & $5-10$ & \\
\hline Primary wastewater solids & $8-15$ & NA & $24-29$ & \\
\hline Swine waste & 6.0 & 28 & NA & \\
\hline Solid cattle manure & $1.6-4.7$ & $1.4-3.3$ & $2.7-5.7$ & \\
\hline Coastal Bermuda grass & 25 & 35.7 & 6.4 & \\
\hline Switchgrass & 45 & 31.4 & 12.0 & \\
\hline Cane bagasse & 36 & 28 & 20 & [14] \\
\hline Cane straw & 36 & 21 & 16 & [15] \\
\hline Maize straw & 36 & 28 & 29 & [14] \\
\hline Corn straw & 39 & 36 & 10 & [16] \\
\hline Barley straw & 44 & 27 & 7 & [16] \\
\hline Rice straw & 33 & 26 & 7 & [16] \\
\hline Oat straw & 41 & 16 & 11 & [16] \\
\hline Cotton straw & 42 & 12 & 15 & [17] \\
\hline Rice shell & 36.1 & 19.7 & 19.4 & [18] \\
\hline Barley bran & 23 & 32.7 & 21 & [19] \\
\hline Pine tree & 44 & 26 & 29 & [14] \\
\hline Card board & 47 & 25 & 12 & [14] \\
\hline Sweet sorghum & 45 & 27 & 21 & [20] \\
\hline
\end{tabular}

\subsection{Cellulose}

Cellulose $\left(\mathrm{C}_{6} \mathrm{H}_{10} \mathrm{O}_{5}\right) \mathrm{x}$ is made up of a linear chain of D-glucose linkages by $\beta-(1,4)$ glycosidic bonds. This linear chain together makes the cellulose fibre. Due to the intra and intermolecular hydrogen bonds [21] linked between the cellulose fibers made it insoluble in water and other organic solvents [22]. The single molecule structure of cellulose is given in Fig. 1.

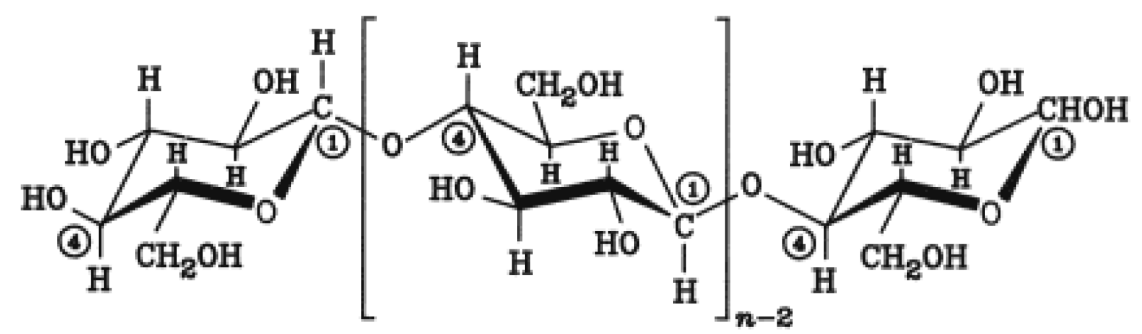

Figure 1. Structure of single cellulose molecule (Adapted from [23]) 


\subsection{Hemicellulose}

Hemicelluloses $\left(\mathrm{C}_{5} \mathrm{H}_{8} \mathrm{O}_{4}\right) \mathrm{m}$ are heterogeneously branched biopolymers (Fig. 2) with different pentoses ( $\beta$-D-xylose, $\alpha$-L-arabinose), hexoses ( $\beta$-D-mannose, $\beta$-D-glucose, $\alpha$-D-galactose) and some uronic acids ( $\alpha$-D-glucuronic, $\alpha$-D-4-0-methyle-galacturonic) [24]. As compare to cellulose fibers, they are easy to hydrolyse because of their branched structure, amorphous. In the fermentation process, hemicelluloses are more relatively sensible to temperature, retention time and hence must be controlled to avoid the formation of furfurals and hydroxymethyl furfurals, which inhibits fermentation [25].

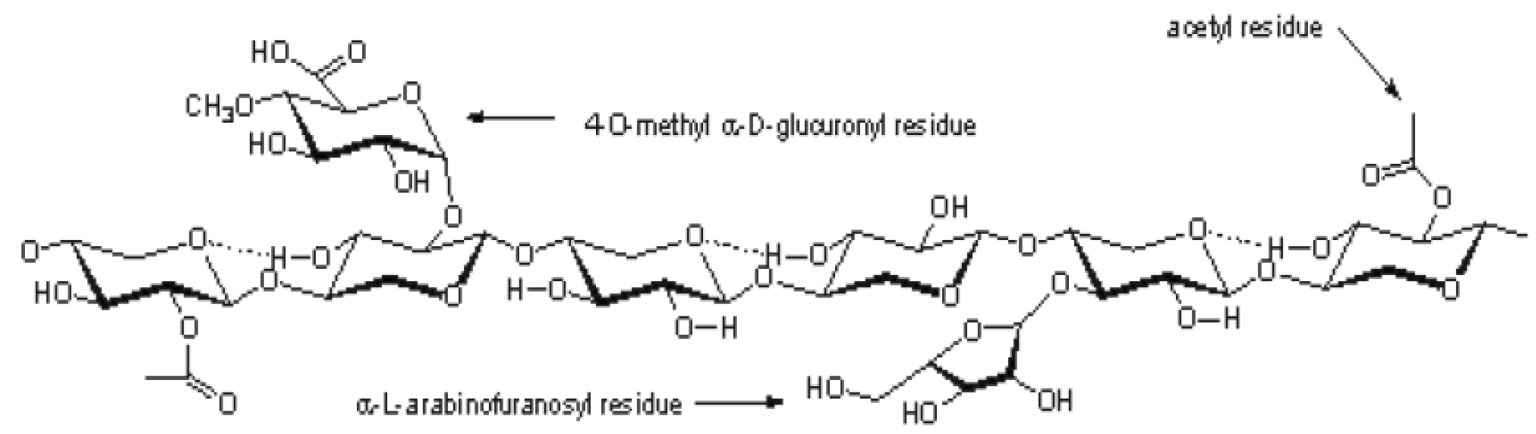

Figure 2. A schematic representation of the hemicellulose in LCB (Adapted from [10])

\subsection{Lignin}

Lignin $\left(\mathrm{C}_{31} \mathrm{H}_{34} \mathrm{O}_{11}\right)_{\mathrm{n}}$ is the stuff that makes the biomass woody in nature. It is a giant polymer molecule with both aliphatic and aromatic portions synthesized from phenylpropanoid precursors (Fig. 3). In general, lignin is made up of three basic building blocks such as P-counmaryl, coniferyl and sinapyl alcohol.<smiles>OC/C=C/c1ccc(O)cc1</smiles>

1<smiles>COc1cc(C=CCO)ccc1O</smiles>

2<smiles>COc1cc(C=CCO)cc(OC)c1O</smiles>

3

Figure 3. P-coumaryl- , coniferyl- and sinapyl alcohol: dominant building blocks of the threedimensional polymer lignin (Adapted from [10])

\section{Overall biochemical conversion process}

Ethanol is currently produced in great amounts from corn-derived starch in the United States and sugar cane- derived sucrose in Brazil. However, these dependent raw materials (first generation) could not supply enough bioethanol for transportation in lower middle-income countries. The ultimate significant raw material with high potential of sustainable production of ethanol is LCB. Moreover, ethanol production from LCB becomes major outlook. Many steps are involved in the production of ethanol from LCB, however, some of the main steps that can be considered are; Conversion of cellulose and hemicellulose to soluble sugars by depolymerization process, Sugar fermentation as well as fermentation of inhibitory compounds and cost effective use of lignin where lignin content can be minimized. 
The polysaccharides obtained from LCB could be hydrolyzed into simple monomer sugar by acid or enzyme treatment. It has been reported that enzymatic hydrolysis are generally more preferred than acid hydrolysis in terms of its environmentally friendly. The monomeric sugars obtained from hydrolysis is used in fermentation to produce ethanol by using microbes like bacteria, yeast, filamentous fungi or genetically modified microorganisms [26]. The final product ethanol is purified by the distillation process. The remaining valuable co-products have many industrial applications and new technologies are under development to convert it into higher value products [27]. The brief schematic diagram of bioethanol conversion from biomass is shown in Fig. 4.

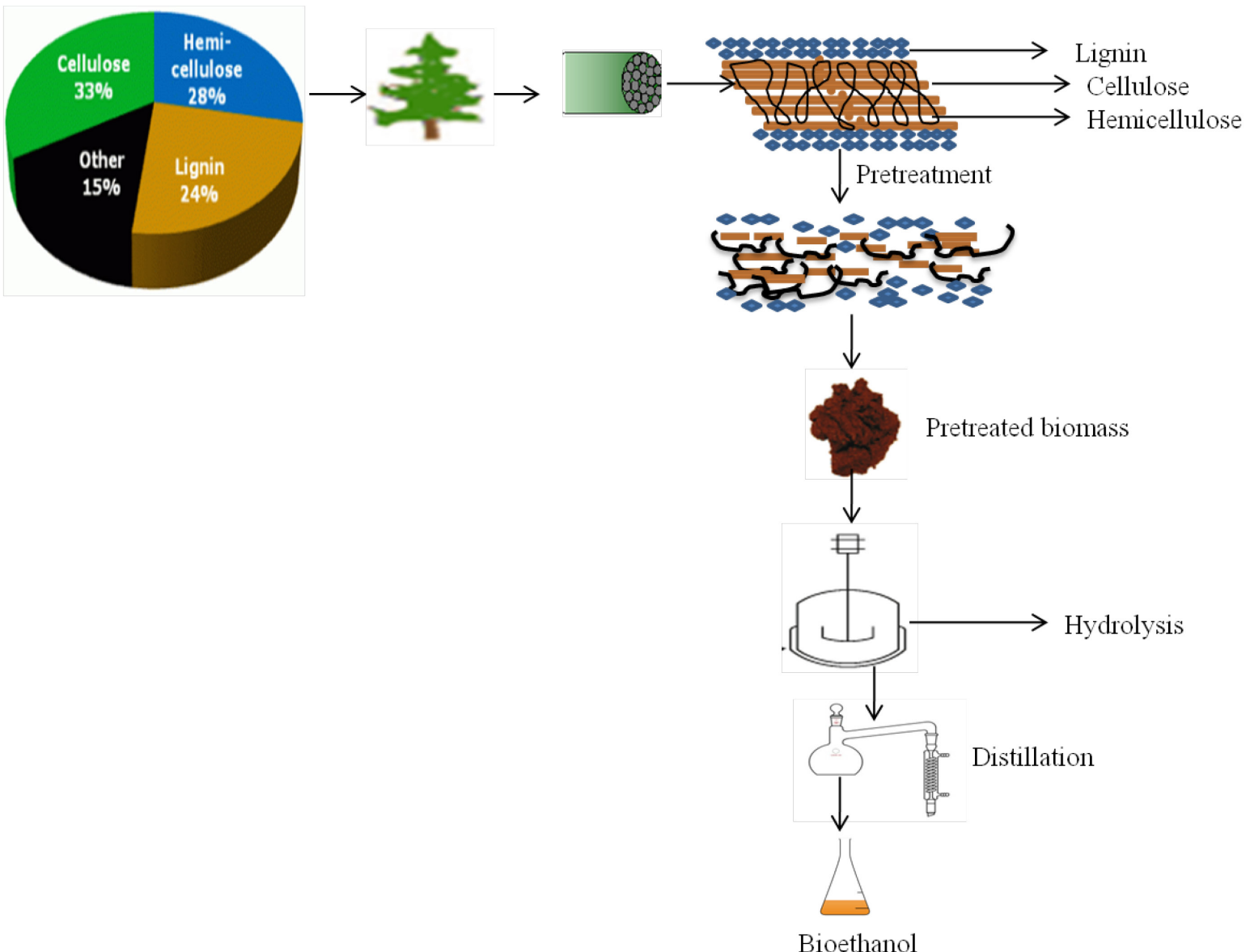

Figure 4. Schematic representation of LCB conversion to bioethanol

\subsection{Pretreatment methods for LCB}

One of the most common and important steps in biochemical conversion of biomass into ethanol is pretreatment technology. The aim of the pretreatment technology is to loosen the strong bond held between the cellulose fibers. The pretreatment induces breaking of the bonds that bind with lignin, cellulose, and hemicelluloses. Pretreatment process is necessary to achieve higher enzymatic degradation in the production of ethanol from LCB. It is essential because: (1) It allows to attack by enzymes (2) avoiding the formation of inhibitory compounds (3) hemicellulose and cellulose recovery (4) size reduction and reducing the cost of materials for construction of fermentation reactors (5) Increases pore size Fig. 5. 


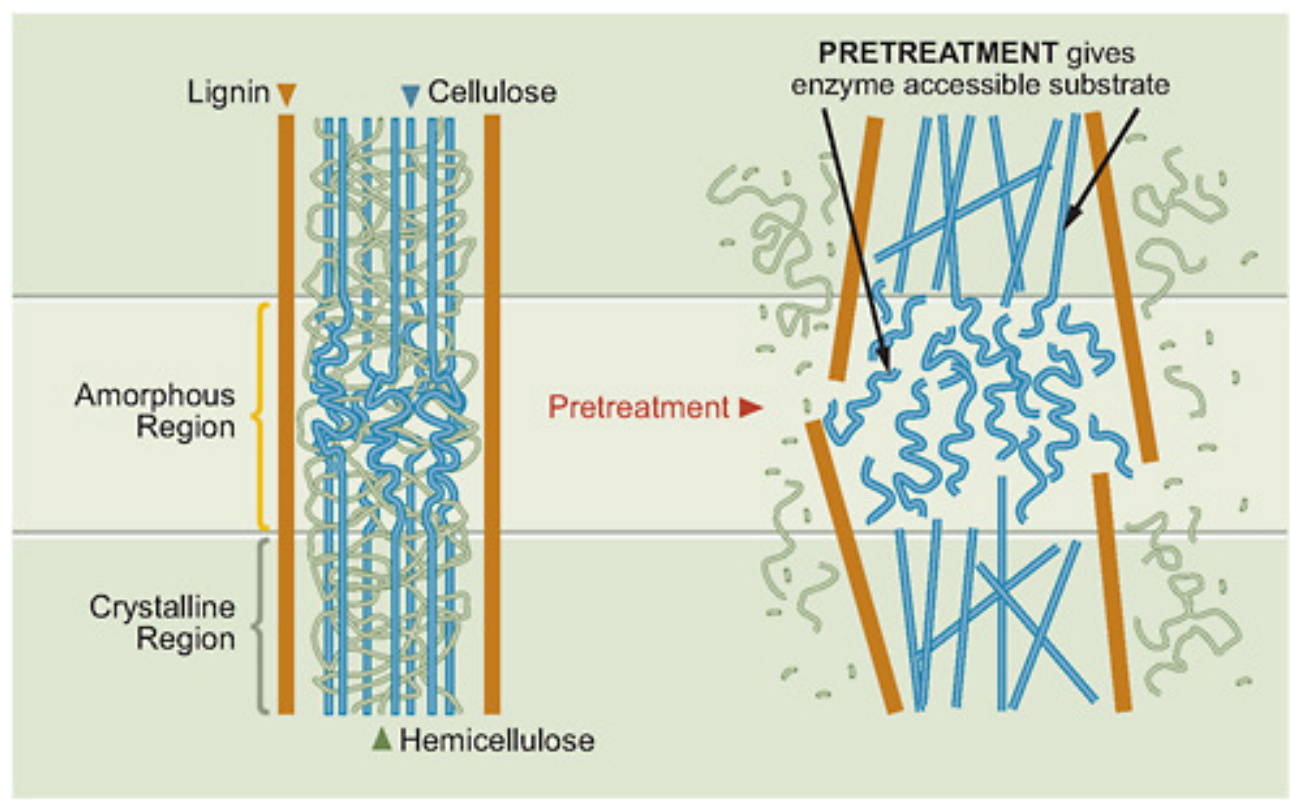

Figure 5. Schematic of pretreatment to disrupt the physical structure of biomass. (Adapted with permission from [28])

There are several methods for pretreatment technology of LCB prior to enzymatic hydrolysis. These methods could be classified into "Physical pretreatment", "Physico-chemical pretreatment", "Chemical pretreatment", and "Biological pretreatment" [29-32]. Schematic outline of pretreatment technologies is given in Fig. 6. The enzyme- based pretreatment is more advantageous than chemical treatment due to higher feasible efficient conversion, no substrate loss, lower reaction temperatures, neutral $\mathrm{pH}$, and use of biodegradable and non- toxic reagents.

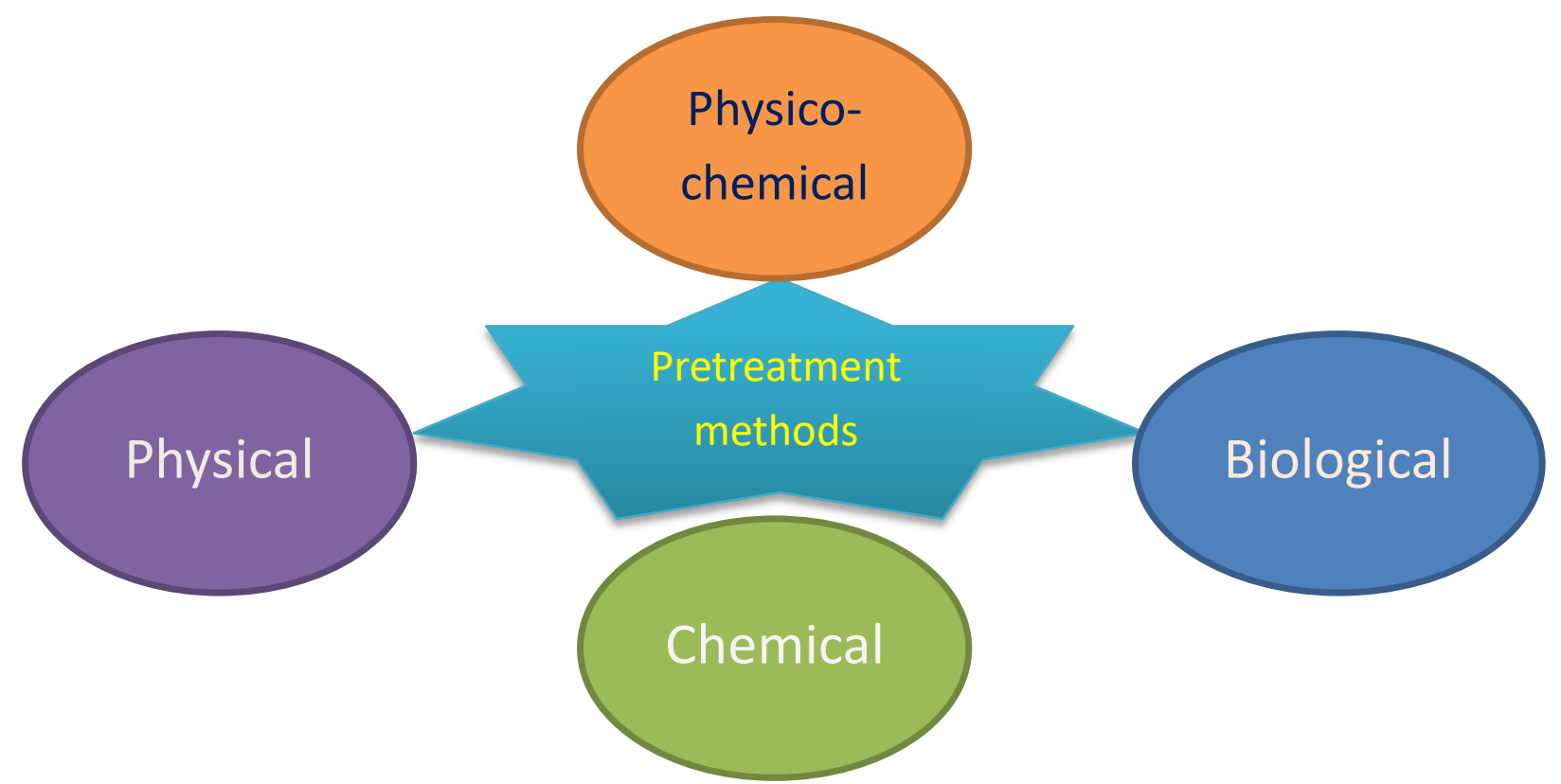

Figure 6. Pretreatment methods for LCB before enzyme hydrolysis.

\subsubsection{Physical pretreatment}

Physical pretreatment is the process of applying mechanical force such as ball milling, tworoll milling, hammer milling, colloid milling, vibrato energy milling [33], chipping, grinding [13] irradiation by gamma rays, electron beam or microwaves etc. to the LCB to reduce its size. This process provides more surface areas, decrease degree of polymerization of cellulose molecules and most importantly decrystallisation. 


\subsubsection{Milling}

There are several types of milling pretreatment method used in bioethanol production. Ball milling, two-roll milling, hammer milling, colloid milling and disk milling are commonly used pretreatment methods. This method enforces to reduce the size of the biomass by applying physical forces. The size of the particle obtained from milling pretreatment depends on the methods enforced. However, 10-30 $\mathrm{mm}$ and $0.2-2 \mathrm{~mm}$ of particle size are achieved in chipping [13]. The milling pretreatment has got some drawbacks which include high energy consumption and high cost of investment. To overcome such drawbacks, wet disk millings are highly adopted. Another disadvantage of milling is its inability to remove lignin from the LCB thereby restricting the enzyme activity [30].

\subsubsection{Irradiation}

Irradiation is another physical pretreatment technology where a ray of light is allowed to impose on LCB. The cellulose component is degraded by irradiation due to dissociation of glycosidic bonds of the cellulose molecules. A high beam irradiation, above $100 \mathrm{MR}$, can disintegrate glucose ring structure [34]. It includes gamma rays, electron beam and microwaves irradiation techniques. By using this technique, it was achieved that the glucose yield of pretreated bagasse became double as compared to untreated one prior to its enzymatic hydrolysis [34]. It helps in improving enzymatic hydrolysis of LCB in the conversion of cellulose to glucose [35-36]. However, some of the irradiation techniques are quite expensive and not applicable for industrial application.

\subsubsection{Microwave mediated pretreatment}

Microwave mediated pretreatment is a combination of the thermal effect of microwave and chemical reagents. Mostly, the chemical used in this process are acids and alkali. The thermal effect in microwave is due to the dielectric heating of the system. This process is rapid and volumetric. The microwave mediated pretreatment have been significantly using in the production of ethanol from LCB. These effects could be used efficiently in improving the ethanol production. It is one of the efficient and modified ways for easily treating the sample in domestic level [37]. In this method, the parameters of microwave conditions are very important in dissociating the cellulose fiber from lignin. In pretreatment of rice straw by this process increases the saccharification by removing lignin and hemicellulose in large amount. Maximum reducing sugar obtained from the process was found to be $1334.79 \mu \mathrm{g} / \mathrm{mL}$ [37].

\subsubsection{Extrusion}

It is a promising physical pretreatment technology for biomass where LCB were subjected to heating, mixing and shearing through the extruder. During this technique, physical and chemical modification of cellulose fibers took place thereby causing defibrillation, fibrillation and shortening of the fibers [38-39]. The technique is highly acceptable due to its high shear, rapid mixing, no furfural formation, easy scale up and no washing and conditioning [38]. Pretreatment of soybean hulls by this technique with screw speed $350 \mathrm{rpm}$, barrel temperature of $80{ }^{\circ} \mathrm{C}$, barrel moisture $40 \%$ could achieve $94.8 \%$ glucose conversion and glucose yield of $0.37 \mathrm{~g} / \mathrm{g}$ biomass [40].

\subsubsection{Chemical pretreatment of LCB}

\subsubsection{Acid hydrolysis}

In this method, dried powdered biomass is treated with the acidic solution under specific temperature for a period of time. The treated biomass was subjected for filtration to separate out the liquid from the unhydrolyzed debris. The hydrolysis reaction constant is directly correlated with hydrogen ion concentration thus the more negative $\mathrm{pKa}$ value of the acid; more is the effective hydrolysis process [41]. There are different acids which can be used in the pretreatment of LCB. For example, sulphuric acid and phosphoric acid are broadly used for treating LCB because of its efficient in hydrolyzing celluloses. Similarly, hydrochloric acid and nitric acid are used and have 
better cellulose to sugar conversion rate than sulphuric acid [42]. However, both acids are more expensive than sulphuric acid. When LCB is treated with acids, hemicellulose portion is degraded faster than cellulose molecules due to a structural configuration [43-44].
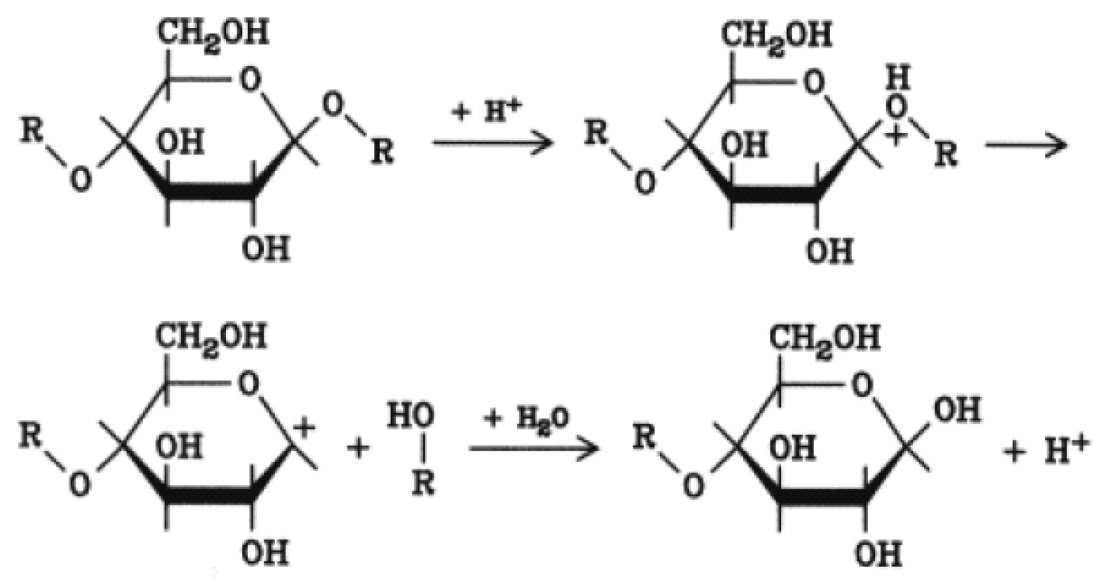

Figure 7. Hydrolysis of cellulose in acidic media [45]

\subsubsection{Dilute acid pretreatment (DAP)}

Industrially made acids can be diluted and used in the pretreatment of biomass for ethanol production. These acids include $\mathrm{H}_{2} \mathrm{SO}_{4}, \mathrm{HNO}_{3}$, and HCL. Different concentration of acids could be used however, $0.2-2.5 \% \mathrm{w} / \mathrm{w}$ is used for treating the LCB in high temperature at $120-210{ }^{\circ} \mathrm{C}$ and pressures [46]. DAP is effective in terms of low acid consumption and process severity. Another advantage is that low acid concentration releases essential nutrients such as sulphur and phosphorus that enhance downstream fermentation of sugars to ethanol [47]. Sometimes two stages processes could be used where both dilute and concentrated acid treatment have to perform. In such case, most of the hemicelluloses solubilized in dilute acid and celluloses hydrolysed in concentrated acid [48-49].

The rate of cellulose conversion to glucose depends on the severity of the acid concentration. Pretreatment of grass, newspaper, potato peeling with the acids such as $\mathrm{H}_{2} \mathrm{SO}_{4}, \mathrm{HNO}_{3}$ or $\mathrm{HCL}$ found that glucose conversion was high when the acid concentration was high [50]. In pretreatment of rye straw with different acids, dilute $\mathrm{HNO}_{3}$ pretreatment was found to be more effective in the conversion of glucose than dilute $\mathrm{H}_{2} \mathrm{SO}_{4}$ [42]. Nevertheless, the main disadvantage of using dilute $\mathrm{HNO}_{3}$ is the by-product formation which is difficult to remove from the system.

Dilute $\mathrm{H}_{3} \mathrm{PO}_{4}$ acid can be used in treating potato peels where $82.5 \%$ of sugar yield was achieved [51] and in corn stover $85 \%$ of glucose, $91.4 \%$ of xylose was yielded [52]. Not only this, some people had tried to combine acids to improve process performance. HCL and $\mathrm{H}_{2} \mathrm{SO}_{4}$ were mixed in pretreating of sweet sorghum bagasse, but the performance was not effective [53]. However, a combination of $\mathrm{H}_{2} \mathrm{SO}_{4}$ and $\mathrm{H}_{3} \mathrm{PO}_{4}$ used in pretreating of oil palm empty fruit recorded high yield of xylose [47] as compared to single acid treatment.

Beside these mineral acids, organic acids such as maleic, fumaric [54] and oxalic [55-56] have been also using in pretreating the biomass of corn stover [57], maple wood [58] etc. It was found that oxalic and maleic acids can degrade more hemicellulose than sulphuric acid [54]. On treatment of corn stover with oxalic acid the best result was obtained at $160{ }^{\circ} \mathrm{C}$ for 10 minutes at a concentration of $200 \mathrm{Mm}$ [57], whereas on maple wood, a total of glucose (87.7\%), xylose (86.9\%) and sugar $(87.4 \%)$ was achieved.

\subsubsection{Concentrated acid pretreatment}

The efficiency of the pretreatment of LCB depends on process adapted and affected by acid/biomass ratio, process temperature, time and concentration of the acid. Acid pretreatment can be effectively used in two ways with respect to temperature. High temperature and low acid concentration (dilute acid pre-treatment) or Low temperature and high acid concentration 
(Concentrated acid pretreatment). Enzymatic hydrolysis of LCB could be improved with treatment of acids at high temperature. Among the acids, sulphuric acid is most widely used while other acids such as $\mathrm{HCL}, \mathrm{HNO}_{3}$ [59] and $\mathrm{H}_{3} \mathrm{PO}_{4}$ were also used in pretreating the biomass. Concentrated acids such as sulphuric $(65-86 \% \mathrm{w} / \mathrm{v})$, hydrochloric $(41 \%)$ and phosphoric $(85 \% \mathrm{w} / \mathrm{w})$ were generally used in pretreating the dried LCB $\left(5-10 \%\right.$ moisture) at low temperature $\left(30-60{ }^{\circ} \mathrm{C}\right)$.

\subsubsection{Chemical additives and acids pretreatment}

Even though, acids treatment have good efficiency and viable ethanol conversion, using of combined treatment with some other additives like chemical agents gives a better product. P-cresol, a phenol derivative with acid enabled complete separation of lignin and cellulose in oil palm empty fruit bunch [60]. Another additive $\mathrm{ZnCl}_{2}$ solution was used with dilute acids [61]. COSLIF (cellulose solvent and organic solvent based lignocelluloses fractionation) is another way of treating biomass with acids where biomass is fractionated by adding concentrated $\mathrm{H}_{3} \mathrm{PO}_{4}$ under condition of $50{ }^{\circ} \mathrm{C}, 1 \mathrm{~atm}$, and $60 \mathrm{~min}$ followed by addition of solvents such as ethanol $(95 \% \mathrm{v} / \mathrm{v})$ under room temperature for $10 \mathrm{~min}$ [62]. COSLIF allows the high enzyme accessibility to cellulose and hence more sugar yield. In a combination of COSLIF and ionic liquids give better digestibility of glucans in a low dose of an enzyme [62].

\subsubsection{Alkali pretreatment}

In alkali pretreatment, LCB are mixed with alkali solutions such as $\mathrm{NaOH}, \mathrm{Ca}(\mathrm{OH})_{2}$, Potassium hydroxide, ammonia [63] and sodium bicarbonate $\left(\mathrm{Na}_{2} \mathrm{CO}_{3}\right)$ [64] at specific temperature and pressure to remove lignin and to degrade ester and glycosidic side chains [65] (Fig. 8). Alkali treatment helps in extraction of a hemicellulose part from the polysaccharide and efficiently increases the accessibility of enzyme to the cellulose. In most of the treatment process, a high concentration of base is required with relatively low temperature and longer time. In contrast, low alkali concentration $(4 \% \mathrm{w} / \mathrm{w})$ at high temperature and pressure could be used with high retention times [66]. After the treatment, two formed of by-products are obtained, a wet solid fraction (Cellulose) and a liquid fraction (Hemicellulose, lignin, inorganic chemicals). The solids portions could be separated by simple filtration and washed with warm water. Washing helps in removing enzyme inhibitors and other chemicals. So in many cases, the bases- $\mathrm{NaOH}$ and $\mathrm{Ca}(\mathrm{OH})_{2}$ have been extensively used in many industries and research field for pretreatment of LCB.
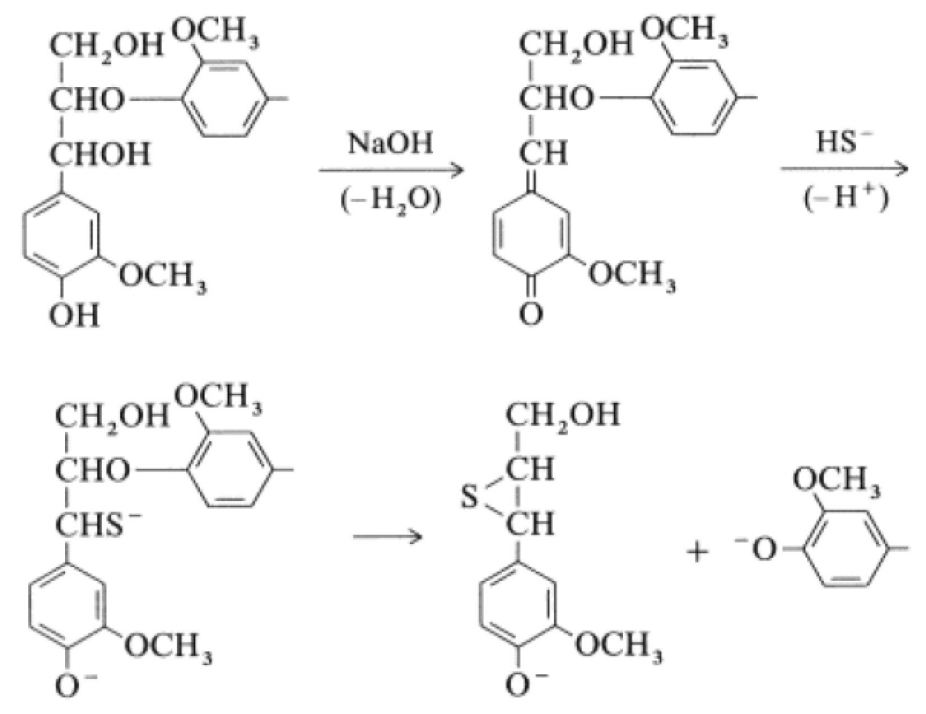

Figure 8. Cleavage of ether bond of lignin in alkaline solution Adapted from [67]

\subsubsection{Sodium hydroxide $(\mathrm{NaOH})$ pretreatment}

Sodium hydroxide is used widely as an agent for treating the biomass of agricultural residues and wood. As compared with acid or oxidative reagents, alkali pretreatment appears to be the most effective technique for breaking the esters bonds in between lignin, hemicellulose, and cellulose 
[68]. Dilute $\mathrm{NaOH}$ treatment loosens the biomass structure, increases the internal surface area, decreases the degree of polymerization and crystallinity, and disrupts the lignin structure [69]. The treatment of biomass with $\mathrm{NaOH}$ is totally depended on the temperature, concentration, and $\mathrm{pH}$ of the solution. Increasing $\mathrm{pH}$ from 10 to 13 increased the removal of lignin from 40 to $80 \% \mathrm{w} / \mathrm{w}$ in the wheat straw at $140{ }^{\circ} \mathrm{C}$ [70]. It is suggested that alkali treatment has more capability to delignify than acid hence $\mathrm{NaOH}$ pretreatment appears to improve enzymatic hydrolysis, sugar yield and biomass utilisation rate [71]. For example, pretreatment for enzymatic conversion of cotton stalk using various agents like sulphuric acid, sodium hydroxide, hydrogen peroxide and ozone treatment, the highest level of delignification $\left(65 \%\right.$ with $\left.2 \% \mathrm{NaOH}, 90 \mathrm{~min}, 121^{\circ} \mathrm{C}\right)$ was achieved by using sodium hydroxide with $60.8 \%$ cellulose conversion rate [72].

\subsubsection{Alkaline peroxide $\left(\mathrm{H}_{2} \mathrm{O}_{2}\right)$ pretreatment}

It is an effective method for pretreatment of LCB such as wheat straw [73], water hyacinth [74] grass stover [75], rice hull [76] and corn stover [77]. In this technique, LCB was soaked with $\mathrm{H}_{2} \mathrm{O}_{2}$ at room temperature, $\mathrm{pH}$ of 11-12 using $\mathrm{NaOH}$, for a period of 6-24 hr. Pretreatment of wheat straw with alkaline peroxide showed excellent sugar yield $(97 \%)$ by enzymatic saccharification [73]. A good result was also got in rice hull with $96 \%$ conversion of sugar at $\left(7.5 \% \mathrm{H}_{2} \mathrm{O}_{2} \mathrm{v} / \mathrm{v}, \mathrm{pH}\right.$ $11.5,35^{\circ} \mathrm{C}, 24 \mathrm{hr}$ ) [76]. One of the major advantages of this treatment is that there is no formation of furfural and hydroxymethylfurfural (HMF). In another report, two stages process could be done based on steam explosion followed by alkaline treatment on wheat straw [78]. Firstly, wheat straw was steam at $200-220{ }^{\circ} \mathrm{C}, 15-22 \mathrm{bar}$. Then it was delignified with $2 \% \mathrm{H}_{2} \mathrm{O}_{2}$ at $50{ }^{\circ} \mathrm{C}, \mathrm{pH} 11.5,5 \mathrm{hr}$. In the first segment of steam explosion pretreatment, there is a significant loss of hemicellulose and $11-12 \%$ lignin removal. In the second segment of post-treatment, $81-88 \%$ lignin was able to remove.

\subsubsection{Lime pretreatment}

Lime (quick lime and slaked lime) has been extensively used as pretreatment agent due to its low cost, easily available, safety in handling, and easy recovery. Lime pretreatment has been considerably applied in many feedstocks with encouraging results. This pretreatment process is usually applied to biomass having low lignin content such as grasses [79], sugarcane bargasse [80] and soft wood. Lime pretreatment improves hydrolysis rates of biomass promoting cellulose accessibility by enzymes [81]. In general, LCB is pretreated with lime water at $130{ }^{\circ} \mathrm{C}$ temperature in the presence of oxygen to enhance delignification [46, 82]. For example, Corn stover was pretreated in non-oxidative condition with an excess supply of calcium hydroxide at $55{ }^{\circ} \mathrm{C}$ for 4 weeks with aeration. A total of $91.3 \%$ glucose and $51.8 \%$ xylose was yielded [83]. Similarly, rice hulls were pretreated with different concentration of lime mixed with water for ethanol production [83]. A total yield of sugar (12.6\%) was achieved at $100 \mathrm{mg}$ lime/g rice hulls in $1 \mathrm{hr}$. It was also found that lime pretreatment enhancing enzymatic saccharification without generating furfural and HMF in the hydrolysate. Despite the merits of lime pretreatment, it has got many drawbacks such as longer reaction time as compared to $\mathrm{NaOH}$ treatment, lesser dissolving rate of water thus requires more volume of water to hold the process.

\subsubsection{Potassium hydroxide (KOH) pretreatment}

Potassium hydroxide $(\mathrm{KOH})$ can be used as an agent for pretreatment of various feedstocks. In pretreating the Switch grass with $\mathrm{KOH}$, the maximum sugar retention was achieved with $99.26 \%$ and sugar yield of $58.2 \%$ [85]. This pretreatment process needs to be extensively investigated for comprehensive cost analysis and may be required to use some other chemical agents in addition to existing protocol.

\subsubsection{Organosolv pretreatment}

This pretreatment process involved extraction of lignin from plant biomass by addition of organic solvent mixture in presence of water with /without a catalyst - such as an acid $(\mathrm{HCl}$, $\left.\mathrm{H}_{2} \mathrm{SO}_{4}\right)$, base $(\mathrm{NaOH})$, or salt $\left(\mathrm{MgCl}_{2}, \mathrm{Fe}_{2}\left(\mathrm{SO}_{4}\right)\right.$ under certain conditions like temperature and 
pressure $[13,86]$. The commonly used solvent are ethanol, methanol, acetone, and ethylene glycol [87]. These solvents hydrolysed the internal bond between lignin and hemicellulose and glycosidic bonds of hemicellulose and cellulose. The maximum temperatures used in the process is $200{ }^{\circ} \mathrm{C}$ and lower temperature is depends on the type of biomass as well as the type of catalyst used. The technique involved pretreatment of biomass and separation of pretreated residues by filtration and washing with distilled water. From such pretreatment processes, usually, three main fractions could be produced- a high purity lignin, a hemicellulose syrup, and relatively pure cellulose. However, variation in the reaction time, temperature, concentration of solvent and dose of the catalyst affects the physical characteristics (crystallinity, degree of polymerisation and length of fibre) of the pretreated residues.

Using of sulphuric acid as catalyst in organosolv pretreatment process has been extensively showing a good yield of sugar despites its corrosive nature. This catalyst degraded the monosaccharide into furfural and 5- HMF [88]. It was found that on the treatment of pine with various catalyst, the most efficient catalyst was with acid treatment which produced maximum ethanol yield [89]. Pretreatment of wheat straw using glycerol based autocatalytic organosolve showed 98\% cellulose retention [90]. Likewise, organosolv pretreatment was also seen in using horticultural waste (HW) for bioethanol production [91]. A modified approached of organosolv method was introduced in HW and Japanese cypress (Chamaecyparis obtusa) where, used of ethanol under mild condition followed by $\mathrm{H}_{2} \mathrm{O}_{2}$ post- treatment [91, 92]. It was achieved that a total of $11.69 \mathrm{~g} / \mathrm{L}$ ethanol was produced from HW hydrolysate after $8 \mathrm{hr}$ of enzymatic hydrolysis and fermentation using Saccharomyces cerevisiae.

\subsubsection{Wet oxidation (WO)}

This technique is one of the common platforms for both ethanol and biogas production. In this technique, biomass is allowed to undergo oxidation in the presence of aqueous solutions with conditions like acid, neutral, and alkali provided with oxygen at an elevated temperature of 125$315^{\circ} \mathrm{C}$, 0.5- $5 \mathrm{MPa}[49,93]$. The process is exothermic, and therefore, it is self-supporting with respect to heat once the reaction starts [94]. The pretreatment process involved the formation of acids from a hydrolytic process and the oxidative reaction. Due to this, cellulose, hemicellulose, and lignin undergo cleavage. Interestingly, hemicelluloses were cleaved to monomeric sugars; whereas lignins undergo oxidation and cellulose degraded to sugars [95]. The pretreated suspension was filtered to separate out the cellulose and hemicellulose substrate. The solid component was washed with de-ionized water before going through enzymatic hydrolysis. Hemicellulose portion was oxidised into intermediates such as carboxylic acids and then cleavage into phenolic compounds, acetaldehydes, and alcohol and then finally degraded into $\mathrm{CO}_{2}$ and $\mathrm{H}_{2} \mathrm{O}$ [96]. One of the main problems of WO pretreatment is about the heat generation, which is very rapid and high because of the fast rate of reaction, hence difficult to control the reactor temperature [97].

Alkaline WO pretreatment helps in reducing the inhibitors of enzymes such as furfural and HMF as compared to acidic and neutral conditions [98-99]. However, the presence of high concentration of phenolic compounds in the biomass is much more toxic than HMF and furfural [23]. It is because phenolic compounds causing partition and loss of integrity of the cell membrane of the fermenting microorganism. Feedstock such as spruce [96,100], wheat straw [101], rape straw [102], and rice husk [103] have been successfully treated with WO and achieved good hydrolysis rate and fermentation yield.

\subsubsection{Sulphite pretreatment}

This pretreatment process is usually used in pulp and paper industry. In this method, ground biomass was mixed with sulphite $\left(\mathrm{Na}_{2} \mathrm{SO}_{3}, \mathrm{NaHSO}_{3}\right.$, etc.) solution $1-10 \% \mathrm{w} / \mathrm{w}$ in acidic, basic, or neutral condition at temperature $80-200{ }^{\circ} \mathrm{C}$ and reaction time of $30-180 \mathrm{~min}$. The pretreated solids were separated by filtration and washed with distilled water to remove unwanted inhibitors. This dried pretreated solid further proceed for enzymatic saccharification. In the entire process, the biomass is allowed to degrade partially and lignin tied up with sulphite to form sulphonates lignin. 
This technique helps in enhancing glucose yields. Later on sulphite forms a sulphonic acid that helps in improving the hydrophilicity of the pretreated substrates [104]. Sometimes, formaldehyde is added in this process to enhance removal of lignin by a formation of sulpho-methyl groups in lignin and high sugar yield was achieved [105]. While treating with corn stover in alkaline $\mathrm{NaHSO}_{3}$ at $140{ }^{\circ} \mathrm{C}$, a total of $78.2 \%$ of sugar was yielded with $92 \%$ lignin removal after enzymatic hydrolysis which was higher than other alkali based methods in similar conditions [106].

Sulphite pretreatment technique is a new emerging promising technique. This technique can be applied in many feedstocks with good results. For example, on corn cob pretreatment, at $156{ }^{\circ} \mathrm{C}$, $1.4 \mathrm{~h}, 7.1 \%$ charge and solid loading of $1: 7.6 \mathrm{w} / \mathrm{w}, 79.3 \%$ of total glucan could be converted into glucose and cellobiose with 72.2\% theoretical ethanol yield [107]. However, the residue of corn cob in treating with sulphite can produce highest glucose of $81.2 \%$ [104]. In a proprietary process, known as Sulfite pretreatment to overcome recalcitrance of lignocelluloses (SPORL) is an emerging method for pretreatment technology.

\subsubsection{Sulfite pretreatment to overcome recalcitrance of lignocelluloses (SPORL)}

In this pretreatment process, biomass is pretreated in a dilute solution of sulphuric acid and sodium bisulphite $\left(\mathrm{NaHSO}_{3}\right)$. The residual solids are separated out from hydrolysate. The lignin portion is removed by sulphonating. SPORL (Sulfite pretreatment to overcome recalcitrance of lignocellulose) pretreatment is a good technology for removal of the recalcitrance of sulfite lignin by $32 \%$ in spruce wood [108] and this technique can be applied to biomass having high lignin content [109-110]. Using SPORL pretreatment technology, it can reduce inhibitors of enzymes up to $65 \%$ and increases in sugar yield from $57 \%$ to $88 \%$ in softwood $[109-110,108]$. In lodgepole pine pretreatment $\left(180{ }^{\circ} \mathrm{C}, 25 \mathrm{~min}\right.$, liquor/wood=3:1/vw $), 276 \mathrm{~L} /$ ton ethanol was yield by SPORL process [110]. In switch grass, treatment with SPORL can digest the raw material more vigorously than other dilute acid and alkali treatment processes [58].

On pretreatment of agave stalk with SPORL, high yield of sugar and lower inhibitors were found as compared to dilute acid and $\mathrm{NaOH}$ treatment [111]. Moreover, this process was also found to be more efficient in sugar recovery than organsolv and steam explosion pretreatments [110]. The process has advantages such as high sugar yield, lignin removal, and biomass recovery. The drawbacks include sugar degradation, a large volume of water required in washing the pretreatment solids, a high cost of recovering pretreatment chemicals etc.

\subsubsection{Glycerol}

Glycerol is a by-product of diesel production. It can be used in the pretreatment of many LCB for ethanol production through fermentation [112]. This pretreatment causes an efficient removal of lignin from biomass. Usually, glycerol and water mixed in the same ratio could be utilised for pretreatment of biomass. In pretreatment of wheat straw $\left(230{ }^{\circ} \mathrm{C}, 4 \mathrm{~h}\right)$ and water hyacinth $\left(230{ }^{\circ} \mathrm{C}\right.$, $1 \mathrm{~h}$ ) with glycerol, a total of $423 \mathrm{mg} / \mathrm{g}$ of reducing sugar was produced for wheat straw and $705 \mathrm{mg} / \mathrm{g}$ was produced for water hyacinth through enzymatic hydrolysis [113]. Glycerol pretreatment with biomass such as poplar, acacia, oak and fir recorded higher cellulose conversion rates as compared to dilute acid treatment [114]. However, a combination of acid and glycerol pretreatment yielded more sugar level than glycerol alone. Pretreatment of sugarcane bagasse at $90{ }^{\circ} \mathrm{C}, 30 \mathrm{~min}$, with acidified glycerol carbonate could produce $80 \%$ glucose and $90 \%$ glucan digestibility [58].

\subsubsection{Physico-chemical pretreatment}

Physico-chemical pretreatment methods are two stage processes where both chemical and physical treatment are combined together to enable the ethanol production [115]. This method comprises a large group of various processes. In this review, we mentioned the important processes which are useful for the LCB conversion.

\subsubsection{Steam explosion (autohydrolysis)}

This pretreatment method is substantially used in both ethanol and biogas production. It is one of the most commonly used methods for LCB pretreatment [116]. This pretreatment method allows 
to open the biomass fibers, and makes the biomass polymers to easily accessible by enzymes in hydrolysis, fermentation, or densification processes. It is also a common pretreatment process for the production of solid biofuel pellets to increase the calorific value. In most of the cases, biomass is treated with high-pressure saturated steam, and then sudden released of pressure makes the materials to undergo an explosive decompression. This allows to degrading hemicelluloses into sugars and lignin transformation due to high temperature, thereby increasing the potential of cellulose hydrolysis in later subsequent steps. In the process, the temperature is set in the range of around $160-260{ }^{\circ} \mathrm{C}$, pressure $0.69-4.83 \mathrm{MPa}, 30 \mathrm{sec}$ to $20 \mathrm{~min}$ before materials are exposed to atmospheric pressure [13]. The steam mixture is held for a certain period to hydrolyze the hemicellulose into sugars, and the process is terminated by an explosive decompression.

In poplar chips pretreated by the steam explosion, a total of $90 \%$ efficiency of enzymatic hydrolysis was achieved in $24 \mathrm{hr}$ as compared to untreated chip, which produces near about 15\% hydrolysis efficiency [117]. Steam explosion method was also applied in sunflower stalk at temperature $180-230{ }^{\circ} \mathrm{C}$ before enzymatic hydrolysis [118]. The highest glucose yield was obtained at $220^{\circ} \mathrm{C}$ and hemicellulose recovery at $210{ }^{\circ} \mathrm{C}$. In another report, poplar and eucalyptus chips were pretreated at $210{ }^{\circ} \mathrm{C}$ for $4 \mathrm{~min}$, wheat straw at $190{ }^{\circ} \mathrm{C}$ for $8 \mathrm{~min}$, Brassica carinata residue at $210{ }^{\circ} \mathrm{C}$ at $8 \mathrm{~min}$ and sweet sorghum bagasses at $210^{\circ} \mathrm{C}$ for $2 \mathrm{~min}$ [119]. In all cases, hemicellulose sugars were extensively solubilised and decreased $75-90 \%$ of xylose content. This technique seems to be cost effective and satisfied most of the requirement in pretreatment process. Therefore, many researchers have tested this method on lab and pilot scale related to industrial scale production. For example, Masonite plants were set up for large scale production [88].

\subsubsection{Catalyzed steam-explosion}

A steam explosion can be discussed in many ways with the addition of various chemical agents. The chemical agents such as $\mathrm{SO}_{2}, \mathrm{H}_{2} \mathrm{SO}_{4}, \mathrm{CO}_{2}$, oxalic acid, etc. are used as a catalytic agent to impregnate the biomass. Use of such catalytic agents prior to steam-explosion has a greater impact on complete hemicellulose removal with better enzymatic digestion and less formation of inhibitory compounds [120]. For example, $\mathrm{SO}_{2}$ impregnated was used in pretreating agricultural residues [110]. Moreover $\mathrm{SO}_{2}$ impregnated biomass is relatively much easy to hydrolyze and ferment the hydrolysate than that of dilute acid impregnated because the later produces inhibitory compounds [121].

In steam explosion treatment of willow biomass with addition of $\mathrm{SO}_{2}$, the maximum glucose yield was found to be $95 \%$ at $1 \% \mathrm{SO}_{2}, 200{ }^{\circ} \mathrm{C}$ [122]. However, the yield of xylose was as low as compared to other pretreatment technologies.

\subsubsection{Ammonium fiber/freeze explosion (AFEX)}

It is one of the alkaline physico-chemical pretreatment processes. In this treatment, biomass is exposed to hot liquid ammonia at $90-100{ }^{\circ} \mathrm{C}$ for $30 \mathrm{~min}$ under high-pressure and then the sudden release of pressure disrupts the structure of LCB leading to increasing digestibility and simultaneously delignifying it [28]. This process can modify or effectively reduce lignin content in biomass without disturbing hemicellulose and cellulose fractions. The optimum condition for pretreatment of LCB by AFEX process varies according to nature of the material. For example, in switch grass optimum conditions of pretreatment were $100{ }^{\circ} \mathrm{C}$, ammonia loading of $1: 1 \mathrm{~kg}$ of ammonia per $\mathrm{kg}$ of dry matter and 5 min retention time [123]. It was also observed that AFEX pretreatment is very much effective in fiber digestion and produces lower a level of inhibitors than acid pretreatment [124-125], and it is a highly effective method for pretreatment of grasses. Further studies on AFEX pretreatment technology found that compounds like 4-hydroxybenzaldehyde, lactate and acetate inhibits fermentation of E. coli KO11 strain [126]. That is why this technology is difficult to have one general method for a different type of biomass pretreatment. But it was observed that for agricultural residues AFEX, wet oxidation and liquid hot water (LHW) pretreatment technologies were more successful [127-129]. 
One of the major advantages of AFEX process is that there is no formation of inhibitory byproducts such as furans [130]. There are certain disadvantages for this process. AFEX pretreatment does not significantly solubilize hemicellulose like other pretreatment processes does. The ammonia present in the process must be recycled after pretreatment to reduce cost and mitigation of environment $[131,13]$.

\subsubsection{Ionic liquids (Green solvents) pretreatment}

Ionic liquids (ILs) are salts having a melting point below $100{ }^{\circ} \mathrm{C}$ with large cations (mostly organic) and small anions (mostly inorganic). It is nonflammable [132], liquid at room temperature [113] with low volatility. ILs could be used in the pretreatment of specific biomass under optimal condition [133]. In IL pretreatment, biomass powder is mixed with solvents in the presence of water and acid. The solution is incubated at a temperature ranging from 80 to $160{ }^{\circ} \mathrm{C}$ for $10 \mathrm{~min}$ to $24 \mathrm{hr}$. Separately, an antisolvent chemical is also added to precipitate the cellulose fraction. The pretreated solids were retained via filtration or centrifugation and washed with distilled water to remove inhibitory. The washed cellulose is lyophilized and later saccharified. The added antisolvent was removed from the IL by the flash distillation process. The remaining IL could be further reuse.

The effectiveness of the pretreatment process in IL could be predicted using Kamlet-Taft hydrogen bond acceptor ability. Higher the $\beta$ value, high is the lignin removal and vice versa [134]. One of the important factor in IL pretreatment is temperature. It influences sugar released, saccharification kinetics and sugar yields of the substrate [135]. Some of the selected biomass which has extensively pretreated with IL are shown in Table 2.

Table 2. ILs pretreatment of some biomass

\begin{tabular}{|c|c|c|c|}
\hline Biomass & Solvent & Temperature $\left({ }^{\circ} \mathrm{C}\right)$, time $(\min )$ & References \\
\hline Eucalyptus & Emim-AC & 150,3 & [136] \\
\hline Poplar & Emim-AC & 120,1 & {$[137]$} \\
\hline Pine & Amim-Cl & 120,5 & [138] \\
\hline Spruce & Amim-Cl & 120,5 & {$[138]$} \\
\hline Energy can bagasse & Emim-AC & $120,0.5$ & [139] \\
\hline Switchgrass & Emim-AC & $120-160,6$ & {$[140]$} \\
\hline Bamboo & Emim-Gly & 120,8 & [141] \\
\hline Wheat straw & Bmim-AC & $100-150,2-6$ & {$[142]$} \\
\hline Rice straw & Ch-Aa & 90,2 & {$[143]$} \\
\hline Water hyacinth & Bmim-AC & $100-150,0.17-1$ & {$[113]$} \\
\hline Kenaf powder & Ch-AC & $110,16 h$ & {$[144]$} \\
\hline Catalpa & Amim-cl & $100,3 \mathrm{~h}$ & {$[145]$} \\
\hline Maple wood flour & Bmim-AC & $90,6 \mathrm{~h}$ & {$[134]$} \\
\hline Willow & Bmim-AC & $120,22 \mathrm{~h}$ & {$[146]$} \\
\hline Red Oak & Emim-AC & $110,16 \mathrm{~h}$ & {$[147]$} \\
\hline Rubber wood & Mmim-ME & $25,0.5 \mathrm{~h}$ & {$[148]$} \\
\hline Rice hulls & Amim-Cl & $90,4 \mathrm{~h}$ & [149] \\
\hline Corn stover & Emim-AC & $140,3 \mathrm{~h}$ & [150] \\
\hline
\end{tabular}

methylimidazolium diethyl phosphate, $\mathrm{Ch}-\mathrm{Aa}$ : Cholinium amino acid, $\mathrm{Ch}-\mathrm{AC}$ : Cholinium acetate,

\subsubsection{Ozonolysis}

The word seems to be a very negative impact, as we know about the ozone depletion in today's scenario. However, ozone could be used as a good agent for pretreatment process. In this process, ozone is sparged into a mixture of biomass and water at specific room temperature in a particular time to solubilize the lignin and hemicellulose [23]. The entire process depends on the type of biomass, the moisture content of the sample, concentration of ozone and ozone flow rate [151]. Ozone pretreatment is not suitable for all biomass. It gives low sugar yield in wheat and rye 
straw [151]. In the treatment of cotton stalk with ozone, the lignin content was reduced 11.97$16.6 \%$. It was observed that the combination of ozone and ethanosolv in Sweetgum, Miscanthus, and loblolly pine gives high delignification and low carbohydrate lost [152]. In addition, combined ozonolysis and autohydrolysis was reported to give high ethanol yield, low waste products, low use of other chemicals and high hemicellulose solubility [152].

Ozonolysis is not so common process as it cannot be applicable to the majority of the biomass. The process is relatively expensive due to a large amount of ozone consumption. But, it has got some advantages; effective removal of lignin, low inhibitory productions, high dry matter concentration (45-60\%) and reactions can be performed in atmospheric conditions [153-154].

\subsubsection{Hydrothermal pretreatment}

It is a new pretreatment technology. It seems to be a very promising process, as organic solvents were not used. This process also lowers the operational cost, which was high in other methods. In this treatment, hemicellulose is removed effectively by subjecting elevated temperature under varied pressure leaving cellulosic biomass susceptible to enzymatic degradation and thereby producing ethanol [155].

Another method called sonification pretreatment is used where biomass is treated with sound waves which help in removing lignin from lignocellulosic [156]. The high frequency of sound wave disrupts the lignin coating and thereby releasing the cellulose and hemicellulose portion.

\subsubsection{Inorganic Salts}

Some of the inorganic salts such as iron (III) chloride [157] and calcium chloride [158] could be used in pretreatment process of some biomass effectively. The salt forms a strong acid solution while dissolved in water. This makes rapid removal of hemicellulose from the biomass. For example, pretreatment of olive tree residue with salt concentration $0.26 \mathrm{M}, 152.6{ }^{\circ} \mathrm{C}, 30 \mathrm{~min}$ got $100 \%$ hemicellulose removal with $36.6 \mathrm{~g}$ glucose/100 g biomass yield [157]. In another report, $\mathrm{CaCl}_{2}$ pretreatment in combination with microwave treatment on corn stover $\left(162.1{ }^{\circ} \mathrm{C}, 12 \mathrm{~min}\right)$ gives much more glucose recovery than that of steam explosion [158].

\subsubsection{Biological pretreatment}

These pretreatment methods employed wood degrading microorganism such as white, brown, soft-rot fungi and bacteria for the production of bioethanol from biomass. The biological pretreatment by white rot fungi is a co-oxidative process where a carbon source is required. The required carbon is supplied from cellulose and hemicelluloses present in the biomass. The employed microorganism modifies the chemical composition of LCB so that enzyme can easily digest the biomass $[159,54,160]$. Different types of fungi can be employed according to the target substrate requirement. In general, brown and soft rots are used to attack the cellulose component of biomass while white rot fungi usually degraded lignin [161]. Among the fungi used in the biological pretreatment of biomass, White rot fungi are the most promising one [162]. In one of the treatment, using four different types of white rot fungi on wood chips for 30 days it was found that Trametes versicolor $\mathrm{MrP} 1$ could hydrolyze maximum substrate up to $45 \%$ and glucose conversion rate of 35\% was achieved [163]. In another treatment of Japanese red pine Pinus densiflora with 3 species of white rot fungi such as Ceriporia lacerata, Stereum hirsutum, and Polyporus brumalis, the most effective in lignin degradation was observed in Stereum hirsutum [54].

Selection of the type of biomass and choosing the species to be used for treatment is an important aspect in biological pretreatment. The pretreatment of biomass like corn stover with Cyathus stercoreus found that there is an improvement of 3 to 5 fold in enzymatic digestibility [164]. While in treating of bamboo with different 35 isolates species of white-rot fungi, lignin degradation was more active in 3 species namely Echinodontium taxodii 2538, Trametes versicolor G20 and Coriolus versicolor B1 out of 35 [165]. 
Biological pretreatment has potential advantages over physical/chemical pretreatments. It is promising technique and has many advantages over chemical treatment method likes, low energy input, mild environment conditions, environment-friendly etc. [13]. However, the characters like slow rate, a large amount of space required, consumption of hemicellulose and cellulose by microorganism shows disadvantages of using biological pretreatment. Therefore, bio-pretreatment faces techno-economic challenges which led to less attractive in commercialization [54].

\subsubsection{Other developing pretreatments methods}

Some of the new methods which were developed to enhance production of bioethanol from LCB by pretreatment technology are used of supercritical $\mathrm{CO}_{2}$, used of weaker acids such as phosphoric acid etc. [166-167]. The Mineral acids, which are used in pretreatment process, have several drawbacks in terms of rusting and toxicity. It requires a reactor that is made up of exotic metals. The weaker acids can use the reactor made up of stainless steel. This helps in lowering the toxic by-products level [166].

The hydrolysate obtained from phosphoric acid treatment were usually resisted by ethanologenic bacteria such as Escherichia coli strains and this bacteria can ferment both the sugars obtained from hemicellulose and cellulose derivatives in a single vessel, this process is termed as simultaneous saccharification and co-fermentation ( $\mathrm{SScF}$ ). SScF shows increased in ethanol yield up to $0.27 \mathrm{~g}$ ethanol/g bagasse (dry weight) [168] as compared to concentrated sulphuric acid pretreatment method.

The overall year wise publication data of pretreatment technologies since 1996 to 2015 (march) is given in Fig. 9. The maximum number of publication came from chemical treatment even though it has many side effects on environmental issues. A complete tough comparison could be obtained in between biological and physical treatment. Physico-chemical treatment is just enhancing parameters in other pretreatment methods, so a number of publications are less. From this, one can conclude about the research work that is going on in a particular field with irrespectiveness of its side effects. However, in days to come more biological pretreatment methods should be adopted in other to produce more ethanol efficiently.

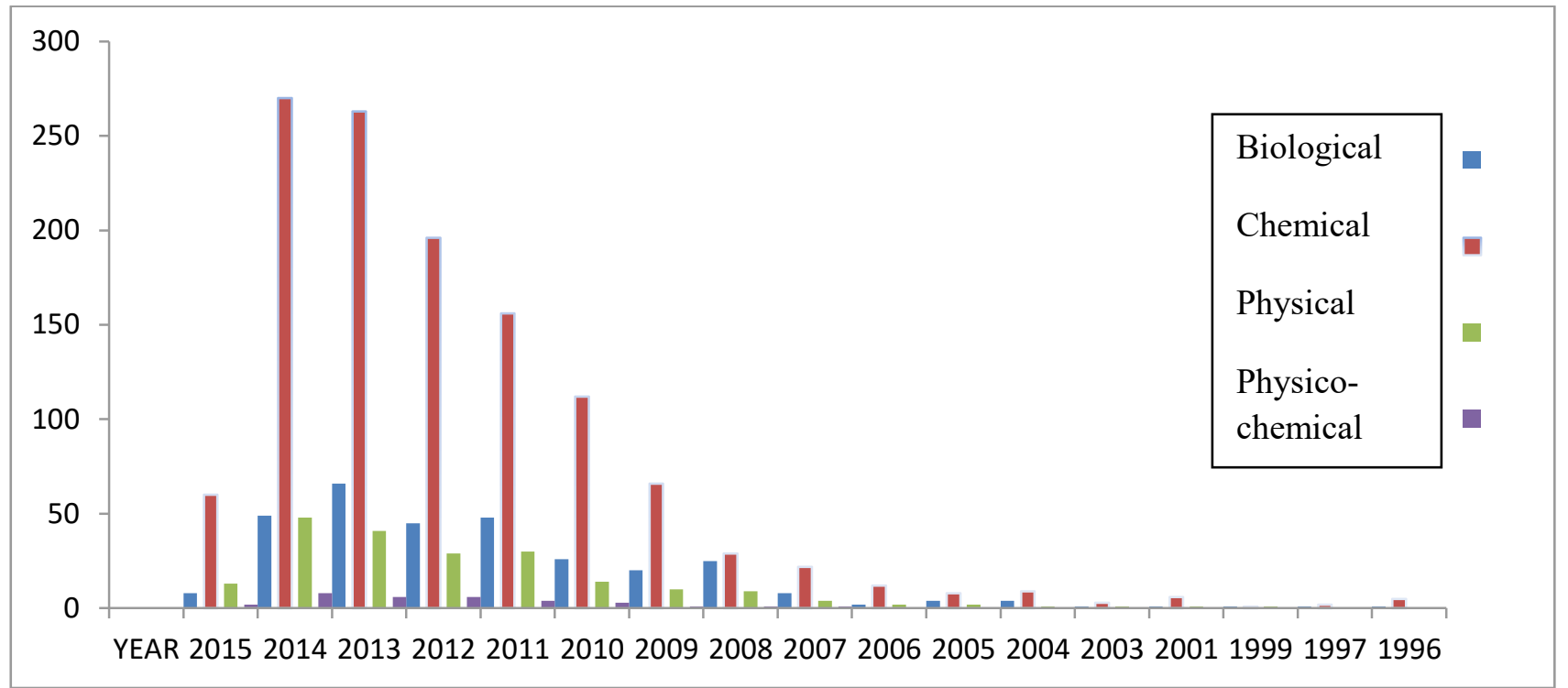

Figure 9. Comparision of pretreatment methods year wise publication from 1996 to 2015 (March). Source: Scopus.

\section{Simultaneous Saccharification and Co-Fermentation}

Fermentation is the final cease in biomass conversion process for bioethanol production. It is usually carried out in different ways like separate hydrolysis and fermentation (SHF), simultaneous saccharification and fermentation (SSF) and simultaneous saccharification and cofermentation (SScF). Firstly, SSF method was introduced by Gulf Oil Company, the US and 
the University of Arkanas [169-170]. Subsequently, the process has become more elaborate and more improvised to yield efficient bioethanol from biomass. In SSF, hydrolysis of cellulose and fermentation process are performed in a single unit with microorganism $S$. cerevisiae. Various reports on bioethanol production had mentioned that SSF is a better process than SHF [171]. Nevertheless, current trends adapted more in the production of bioethanol with less process complexity, solid-liquid separation, neutralization of hydrolysate toxins (SHF) and co-fermentation of hexose and pentose (SScF). Hydrolysate resistant biocatalysts such as E.coli MM160 [168, 172] and S.cerevisiae 424A [173- 177] has been developed. Lignin + SScF and SScF processes combine both C-6 and C-5 sugar fermentation in a single and more modified unit process simplification has been developed. These gave more yield of bioethanol as compared to SHF.

\section{Conclusions and Future Perspective}

The commercial production of bioethanol has been started around at 1975, during energy crisis at Brazil. In other countries after 35 years of research and development, commercial plants for the production of bioethanol have become reality. Therefore, during next decade, bioethanol technology is likely to embark the bio-refineries all over the world for transportation and domestic use. Extensive research is going on to develop the economically feasible bioethanol production that can meet the ethanol demand of the world. The challenges led to the production of around 30 billion gallons of bioethanol by 2020. Many advanced pretreatment technologies have been developed but dilute acid and steam explosion are commercially feasible. A major improvement has been made on genetic engineering of biomass or enzymes even production of cellulase inside plant biomass. However, the cost of the cellulase enzymes is also a main concerned. Approaches have been made to minimize enzyme cost providing more robust cellulase production. Genetic engineering is one such major area where it may play a potential role for the future development of biofuel production as well as in agriculture sector. Multiple transgenic strategies need to be developed to tackle the lack of metabolic pathways. Apparently, production of different chemicals, using of lignin by- products, and integration of ethanol production with power and heat plant are anticipated to take place, owing to improved financial returns and cost effective in the market. However, the existing pretreatment technologies also need to improve and possible process simplifications are the major targets in near days to come.

\section{Acknowledgement}

The author is highly thankful to the Vice chancellor of CUTM, Bhubaneswar for providing the facilities.

\section{Conflict of interest}

Authors declared there is no conflict of interest

\section{References}

[1] H. Chum et al. (Eds.), Bioenergy 'IPCC Special Report on Renewable Energy Sources and Climate Change Mitigation, Cambridge University Press, United Kingdon and New York, NY, USA, 2011.

[2] B. Nicolas, M.I. Mohamad Nasir, A.R. Afidah, Biomass to bioethanol: Initiatives of the future for lignin, ISRN Materials Science. (2011) ID 461482.

[3] S.N. Naik et al., Production of first and second generation biofuels: A comprehensive review, Renewable and Sustainable Energy Reviews. 14(2) (2010) 578-597.

[4] P. Wei et al., A review of membrane technology for bioethanol production, Renewable and Sustainable Energy Reviews. 30 (2013) 388-400. 
[5] P.S. Nigam, A. Singh, Production of liquid biofuels from renewable resources, Prog. Energy Combust Sci. 37 (2011) 52-68.

[6] Ó.J. Sánchez, C.A.Cardona, Trends in biotechnological production of fuel ethanol from different feedstocks, Bioresource Technology. 99 (2008) 5270-5295.

[7] A. Tasneem, S.A. Abbas, Biomass energy and the environmental impacts associated with its production and utilization, Renewable and Sustainable Energy Reviews. 14 (2010) 919-937.

[8] J. Parez-Garcia et al., An assessment of carbon pools, storage and wood products market substitution using life-cycle analysis Results, Wood Fiber Science. 37 (2005) 140-148.

[9] P.H. Raven, Biology of plants (6th edition), W.H. Freeman and company/Worth Publishers, 1992.

[10] Kirk-Othmer Encyclopedia of Chemical Technology, 4th edition (2001), 27 volumes. ISBN: 0471484946

[11] S. Prasad, A. Singh, H.C. Joshi, Ethanol as an alternative fuel from agricultural, industrial and urban residues, Resource Conserve Recycle. 50 (2007) 1-39.

[12] F. John et al., Ethanol production of Banana shell and cassava starch, Dyna Universidad Nacional de Colombia. 73 (2006) 21-27.

[13] Y. Sun, J. Cheng, Hydrolysis of lignocellulosic materials for ethanol production: a review, Bioresour. Technol. 83 (2002) 1-11.

[14] V.A. Awafo, D.S. Chahal, B.K. Simpson, Optimization of ethanol production by Saccharomyces cerevisiae (ATCC 60868) and Pichia stipitis Y-7124: A response surface model for simultaneous hydrolysis and fermentation of wheat straw, Journal of Food Biotechnology. 22 (1998) 49-97.

[15] G. Atranikian, Microbial Degradation of Starch, in: Microbial Degradation of Natural Products. Ed. G. Winkelmann. VCH Verlag, 28-56, Weinheim, Germany, 1992.

[16] A.G. Berlin et al., Weak lignin-binding enzymes. A novel approach to improve activity of cellulases for hydrolysis of lignocellulosics, Applied Biochemistry \& Biotechnology. 121-124 (2005) 163-170.

[17] G.J.V. Betancur, Avanços em biotecnologia de hemicelulose para produção de etanol por Pichia stipitis. Dissertação de Mestrado, Escola de Química da UFRJ, Rio de Janeiro, 2005.

[18] A. Breen, F.L. Singleton, Fungi in lignocellulose breakdown and biopulping, Current Opinion Biotechnology. 10(3) (1999) 252-258.

[19] B.S. Bower, Fusion proteins of an exocellobiohydrolase and an endoglucanase for use in the saccharification of cellulose and hemicellulose. US patent 2005093073, (2005).

[20] M. Kim, D.F. Day, Composition of sugar cane, energy cane, and sweet sorghum suitable for ethanol production at Louisiana sugar mills, Journal of Industrial Microbiology \& Biotechnology. 38(7) (2011) 803-807.

[21] M.F. Li et al., Sodium hydroxide/urea based pretreatment of bamboo for bioethanol production:characterization of the cellulose rich fraction, Industrial Crops and Products. 32 (2010) 551-559.

[22] R.P. Swatloski et al., Dissolution of cellose with- ionic liquids, JACS. 124(18) (2002) 49744975.

[23] P.F.H. Harmsen et al., Literature Review of Physical and Chemical Pretreatment Processes for Lignocellulosic Biomass, Energy Research Centre of Netherlands (ECN), 2010.

[24] F.M. Girio et al., Hemicelluloses for fuel ethanol: a review, Bioresource Technology, 101 (2010) 4775-800. 
[25] H.M. Sohrab et al., Lignocellulosic biomass to bioethanol, a comprehensive review with a focus on pretreatment, Sustainable Energy Reviews. 27 (2013) 77-93.

[26] Z. Yi, P. Zhongli, Z. Ruihong, Overview of biomass pretreatment for cellulosic ethanol production, Int. J. Agric. Biol. Eng. 2(3) (2009) 51.

[27] S. Fernando et al., Biorefineries: current status, challenges, and future direction, Energy Fuels. 20 (2006) 1727-1737.

[28] N. Mosier et al., Features of promising technologies for pretreatment of lignocellulosic biomass, Bioresource Technology. 96 (2005) 673-686.

[29] D.J. Schell, B. Duff, Review of pilot plant programs for bioethanol conversion, in: C.E. Wyman (Ed.), Handbook on bioethanol: Production and utilization. 7 (1996) 381-394.

[30] A. Berlin et al., Inhibition of cellulase, xylanase and beta-glucosidase activities by softwood lignin preparations, J. Biotechnol. 125 (2006) 198-209.

[31] K. Karimi, S. Kheradmandinia, M.J. Taherzadeh, Conversion of rice straw to sugars by dilute acid hydrolysis, Biomass Bioenerg. 30 (2006) 247-253.

[32] L. Fan, Y. Lee, M. Gharpuray, The nature of lignocellulosics and their pretreatments for enzymatic hydrolysis, Adv. Biochem. Eng. Biotechnol. 23 (1982) 158-183.

[33] M.J. Taherzadeh, K. Karimi, Pretreatment of lignocellulosic wastes to improve ethanol and biogas production: a review, Int. J. Mol. Sci. 9 (2008) 1621-1651.

[34] M. Kumakura, I. Kaetsu, Effect of radiation pretreatment of bagasse on enzymatic and acid hydrolysis, Biomass, 3 (1983) 199-208.

[35] M. Kumakura, I. Kaetsu, Pretreatment by radiation and acids of chaff and its effect on enzymatic hydrolysis of cellulose, Agr. Wastes. 9 (1984) 279-287.

[36] S.A.S. Mamar, A. Hadjadj, Radiation pretreatments of cellulose materials for the enhancement of enzymatic hydrolysis, Radiat. Phys. Chem. 35 (1990) 451-455.

[37] R. Singh et al., Microwave assisted alkali pretreatment of rice straw for enhancing enzymatic digestibility, Journal of Energy. 2014 (2014) Article ID 483813.

[38] C. Karunanithy, K. Muthukumarappan, Optimization of alkali soakingand extrusion pretreatment of prairie cord grass for maximum sugar recovery by enzymatic hydrolysis, Biochemical Engineering Journal. 54 (2011) 71-82.

[39] P. Alvira et al., Pretreatment technologies for an efficient bioethanol production process based on enzymatic hydrolysis: A review, Bioresource Technology. 101 (2010) 4851-4861.

[40] J. Yoo et al., Thermo-mechanical extrusion pretreatment for conversion of soybean hulls to fermentable sugars, Bioresource Technology. 102 (2011) 7583-7590.

[41] O. Bobleter, Hydrothermal degradation of polymers derived from plants, Progress in Polymer Science. 5 (1994) 797-841.

[42] M. Tutt, T. Kikas, J. Olt, Influence of different pretreatment methods on bioethanol production from wheat straw, Agronomy Research Biosystem Engineering. 1 (2012) 269276.

[43] R. Samuel et al., Solid-state NMR characterization of switchgrass cellulose after dilute acid pretreatment, Biofuels. 1(1) (2010) 85-90.

[44] M. Foston, A.J. Ragauskas, Changes in lignocellulosic supramolecular and ultrastructure during dilute acid pretreatment of Populus and switchgrass, Biomass and Bioenergy. 34(12) (2010) 1885-1895.

[45] H. Krassig, J. Schurz, Ullmann's Encyclopedia of Industrial Chemistry, Sixth edition, Weinheim, Germany, Wiley-VCH, 2002. 
[46] L. Tao et al., Process and technoeconomic analysis of leading pretreatment technologies for lignocellulosic ethanol production using switchgrass, Bioresource Technology. 102(24) (2011) 11105-11114.

[47] D. Zhang et al., Optimization of dilute acid-catalyzed hydrolysis of oil palm empty fruit bunch for high yield production of xylose, Chemical Engineering Journal. 181(182) (2012) 636-642.

[48] F.K. Kazi, J. Fortman, R. Anex, Techno-Economic analysis of biochemical scenarios for production of cellulosic ethanol, Tech. Rep. NREL/TP-6A2-46588, NREL, 2010.

[49] F. Talebnia, D. Karakashev, I. Angelidaki, Production of bioethanol from wheat straw: an overview on pretreatment, hydrolysis and fermentation, Bioresource Technology. 101(13) (2010) 4744-4753.

[50] A. Li, B. Antizar-Ladislao, M. Khraisheh, Bioconversion of municipal solid waste to glucose for bio-ethanol production, Bioprocess and Biosystems Engineering. 30(3) (2007) 189-196.

[51] P. Lenihan et al., Dilute acid hydrolysis of lignocellulosic biomass, Chemical Engineering Journal. 156(2) (2010) 395-403.

[52] A. Avci et al., Response surface optimization of corn stover pretreatment using dilute phosphoric acid for enzymatic hydrolysis and ethanol production, Bioresource Technology. 130 (2013) 603-612.

[53] E. Heredia-Olea, E. P'erez-Carrillo, S.O. Serna-Sald'ivar, Effects of different acid hydrolyses on the conversion of sweet sorghum bagasse into C5 and C6 sugars and yeast inhibitors using response surface methodology, Bioresource Technology. 119 (2012) 216-223.

[54] J.W. Lee, T.W. Jeffries, Efficiencies of acid catalysts in the hydrolysis of lignocellulosic biomass over a range of combined severity factors, Bioresource Technology. 102(10) (2011) 5884-5890.

[55] J.W. Lee et al., The roles of xylan and lignin in oxalic acid pretreated corncob during separate enzymatic hydrolysis and ethanol fermentation, Bioresource Technology. 101(12) (2010) 4379-4385.

[56] X. Li et al., Oxalic acid pretreatment of rice straw particles and loblolly pine chips: release of hemicellulosic carbohydrates, Tappi Journal. 10(5) (2011.) 41-45.

[57] G.Y.S. Mtui, Oxalic acid pretreatment, fungal enzymatic saccharification and fermentation of maize residues to ethanol, African Journal of Biotechnology. 11(4) (2012) 843-851.

[58] T. Zhang, R. Kumar, C.E. Wyman, Sugar yields from dilute oxalic acid pretreatment of maple wood compared to those with other dilute acids and hot water, Carbohydrate Polymers. 92 (2013) 334-344.

[59] M.J. Taherzadeh, K. Karimi, Acid-based hydrolysis processes for ethanol from lignocellulosic materials: A review, BioResources. 2 (2007) 472-499.

[60] M. Zainudin et al., Utilization of glucose recovered by phase separation system from acidhydrolysed oil palm empty fruit bunch for bioethanol production, Pertanika Journal of Tropical Agricultural Science. 35(1) (2012) 117-126.

[61] A.M. Azzam, Saccharification of bagasse cellulose pretreated with $\mathrm{ZnCl} 2$ and $\mathrm{HCl}$, Biomass Bioenerg. 12 (1987) 71-77.

[62] N. Sathitsuksanoh, Z. Zhu, Y.H.P. Zhang, Cellulose solvent- and organic solvent-based lignocellulose fractionation enabled efficient sugar release from a variety of lignocellulosic feedstocks, Bioresource Technology. 117 (2012) 228-233. 
[63] J. Xu, X. Zhang, J.J. Cheng, Pretreatment of corn stover for sugar production with switchgrass-derived black liquor, Bioresource Technology. 111 (2012) 255-260.

[64] C. Vaccarino et al., Effect of $\mathrm{SO} 2, \mathrm{NaOH}$ and $\mathrm{Na} 2 \mathrm{CO} 3$ pretreatments on the degradability and cellulase digestibility of grape marc, Biol. Waste. 20 (1987) 79-88.

[65] N. Sarkar et al., Bioethanol production from agricultural wastes: an overview, Renewable Energy. 37(1) (2012) 19-27.

[66] H.Y. Yoo et al., Optimization of sodium hydroxide pretreatment of canola agricultural residues for fermentable sugar production using statistical method, in: Proceedings of the International Conference on Future Environment and Energy (IPCBEE '12), vol. 28, 2012.

[67] S.Y. Lin, I.S. Lin, Ullmann's Encyclopedia of Industrial Chemistry, Sixth edition, Wein-heim, Germany, Wiley-VCH, 2002.

[68] M. Gaspar, G. Kalman, K. Reczey, Corn fiber as a raw material for hemicellulose and ethanol production, Process Biochem. 42 (2007) 1135-1139.

[69] C. Bougrier, J.P. Delgenes, H. Carrere, Combination of thermal treatments and anaerobic digestion to reduce sewage sludge quantity and improve biogas yield, Process Saf. Environ. Protect. 84 (2006) 280-284.

[70] M. Pedersen, K.S. Johansen, A.S. Meyer, Low temperature lignocellulose pretreatment: effects and interactions of pretreatment $\mathrm{pH}$ are critical for maximizing enzymatic monosaccharide yields from wheat straw, Biotechnology for Biofuels. 4 (2011) article 11.

[71] M. Ioelovich, E. Morag, Study of enzymatic hydrolysis of mild pretreated lignocellulosic biomasses, BioResources. 7(1) (2012) 1040-1052.

[72] R.A. Silverstein et al., A comparison of chemical pretreatment methods for improving saccharification of cotton stalks, Bioresource Technology. 98(16) (2007) 3000-3011.

[73] B.C. Saha, M.A. Cotta, Ethanol production from alkaline peroxide pretreated enzymatically saccharified wheat straw, Biotechnol. Progr. 22 (2006) 449-453.

[74] D. Mishima et al., Comparative study on chemical pretreatments to accelerate enzymatic hydrolysis of aquatic macrophyte biomass used in water purification processes, Bioresource Technol. 97 (2006) 2166-2172.

[75] G. Banerjee et al., Rapid optimization of enzyme mixtures for deconstruction of diverse pretreatment/biomass feedstock combinations, Biotechnology for Biofuels. 3 (2010) article 22.

[76] B.C. Saha, M.A. Cotta, Enzymatic saccharification and fermentation of alkaline peroxide pretreated rice hulls to ethanol, Enzyme Microb. Tech. 41 (2007) 528-532.

[77] G. Banerjee et al., Alkaline peroxide pretreatment of corn stover: effects of biomass, peroxide, and enzyme loading and composition on yields of glucose and xylose, Biotechnology for Biofuels. 4 (2011) article 16.

[78] X.F. Sun et al., Characteristics of degraded cellulose obtained from steam-exploded wheat straw, Carbohyd. Res. 340 (2005) 97-106.

[79] R.J. Garlock et al., Comparative material balances around pretreatment technologies for the conversion of switchgrass to soluble sugars, Bioresource Technology. 102(24) (2011) 1106311071.

[80] S.C. Rabelo, R.M. Filho, A.C. Costa, A comparison between lime and alkaline hydrogen peroxide pretreatments of sugarcane bagasse for ethanol production, Applied Biochemistry and Biotechnology. 148(1-3) (2008) 45-58. 
[81] R. Kumar, C.E. Wyman, Cellulase adsorption and relationship to features of corn stover solids produced by leading pretreatments, Biotechnology and Bioengineering. 103(2) (2009) 252-267.

[82] M. Falls, M.T. Holtzapple, Oxidative lime pretreatment of alamo switchgrass, Applied Biochemistry and Biotechnology. 165(2) (2011) 506-522.

[83] S. Kim, M.T. Holtzapple, Lime pretreatment and enzymatic hydrolysis of corn stover, Bioresour Technol. 96 (2005) 1994-2006.

[84] B.C. Saha, M.A. Cotta, Lime pretreatment, enzymatic saccharification and fermentation of rice hulls to ethanol, Biomass Bioenergy. 32 (2008) 971-977.

[85] R. Sharma et al., Potential of potassium hydroxide pretreatment of Switch grass for fermentable sugar production, Appl. Biochem. Biotechnol. 169(3) (2012) 761-772.

[86] M.G. Alriols et al., Agricultural palmoil tree residues as Raw material for cellulose, lignin and hemicelluloses production by ethylene glycol pulping process, Chemical Engineering Journal. 148(1) (2009) 106-114.

[87] M. Ichwan, T.W. Son, Study on organosolv pulping methods of oil palm biomass, in: International Seminar on Chemistry, 2011, pp. 364-370.

[88] H.L. Chum et al., Evaluation of pretreatments of biomass for enzymatic hydrolysis of cellulose. Solar Energy Research Institute: Golden, Colorado, 1985, pp. 1-64.

[89] N. Park et al., Organosolv pretreatment with various catalysts for enhancing enzymatic hydrolysis of pitch pine (Pinus rigida), Bioresource Technology. 101(18) (2010) 7046-7053.

[90] F. Sun, H. Chen, Organosolv pretreatment by crude glycerol from oleochemicals industry for enzymatic hydrolysis of wheat straw, Bioresour. Technol 99 (2008) 5474-5479.

[91] Geng A, Xin F, Ip J (2012) Ethanol production from horticultural waste treated by a modified organosolv method. Bioresour Technol 104:715-721.

[92] Hideno A, Kawashima A, Endo T, Honda K, Morita M (2013) Ethanol-based organosolv treatment with trace hydrochloric acid improves the enzymatic digestibility of Japanese cypress (Chamaecyparis obtusa) by exposing nanofibers on the surface. Bioresour Technol 18:64-70.

[93] Schutt BD and Abraham MA, "Evaluation of a monolith reactor for the catalytic wet oxidation of cellulose, Chemical Engineering Journal, vol. 103, no. 1-3, pp. 77-88, 2004.

[94] Schmidt, A.; Thomsen, A. Optimization of wet oxidation pretreatment of wheat straw. Bioresource Technol. 1998, 64, 139-151.

[95] Schultz, T.P.; McGinnis, G.D.; Biermann, C.J. Similarities and differences in pretreating woody biomass by steam explosion, wet oxidation, autohydrolysis, and rapid steam hydrolysis/continuous extraction. In Proceedings of Annual Symposium on Energy from Biomass and Wastes, Lake Buena Vista, FL, USA, 1984.

[96] Palonen H, Thomsen AB, Tenkanen M, Schmidt AS and Viikari L, Evaluation of wet oxidation pretreatment for enzymatic hydrolysis of softwood, Applied Biochemistry and Biotechnology A, vol. 117, no. 1, pp. 1-17, 2004.

[97] Garrote, G.; Dominguez, H.; Parajo, J.C. Hydrothermal processing of lignocellulosic materials. Holz Als Roh-und Werkst. 1999, 57, 191-202.

[98] Mart'in C, Gonz'alez Y, Fern'andez T, and Thomsen AB “Investigation of cellulose convertibility and ethanolic fermentation of sugarcane bagasse pretreated by wet oxidation and steam explosion, Journal of Chemical Technology and Biotechnology, vol. 81, no. 10, pp. 1669-1677, 2006. 
[99] Thomsen AB and Schmidt S, Further Development of Chemical and Biological Processes for Production of Bioethanol: Optimisation of Pre-Treatment Processes and Characterisation of Products, Riso-R-1110(EN), Riso National Laboratory, Roskilde, Denmark, 1999.

[100] Rovio S, Kallioinen A, Tamminen T, Hakola M, Leskel M, and Siika-ahoa M, “Catalysed alkaline oxidation as a wood fractionation technique, BioResources, vol. 7, no. 1, pp. 756$776,2012$.

[101] Klinke HB, Olsson L, Thomsen AB, and Ahring BK, “Potential inhibitors from wet oxidation of wheat straw and their effect on ethanol production of Saccharomyces cerevisiae: wet oxidation and fermentation by yeast, Biotechnology and Bioengineering, vol. 81, no. 6, pp. 738-747, 2003.

[102] Arvaniti E, Bjerre AB, and Schmidt JE, “Wet oxidation pretreatment of rape strawfor ethanol production, Biomass and Bioenergy, vol. 39, pp. 94-105, 2012.

[103] Banerjee S, Sen R, Pandey RA , Tapan C, Dewanand S, Balendu SG, Sandeep M “ Evaluation of wet air oxidation as a pretreatment strategy for bioethanol production from rice husk and process optimization, Biomass and Bioenergy, vol. 33, no. 12, pp. 1680-1686, 2009.

[104] Bu L, Xing Y, Yu H, Gao Y, and Jiang J, “Comparative study of sulfite pretreatments for robust enzymatic saccharification of corn cob residue, Biotechnology for Biofuels, vol. 5, article 8, 2012.

[105] Jin Y, Yang L, Jameel H, Chang HM, and Phillips R, “Sodium sulfite-formaldehyde pretreatment of mixed hardwoods and its effect on enzymatic hydrolysis, Bioresource Technology, vol. 135, pp. 109-115, 2013.

[106] Qiang L, Yang G, Haisong W, Bin L, Chao L, Guang Y, Xindong M Comparison of different alkali-based pretreatments of corn stover for improving enzymatic saccharification, Bioresource Technology 125 (2012) 193-199

[107] Cheng KK, Wang W, Zhang JA, Zhao Q, Li JP, and Xue JW, “Statistical optimization of sulfite pretreatment of corncob residues for high concentration ethanol production, Bioresource Technology, vol. 102, no. 3, pp. 3014-3019, 2011.

[108] Shuai L, Yang Q, Zhu JY, Lu FC, Weimer PJ, Ralph J, Pan XJ (2010). Comparative study of PORL and dilute-acid pretreatments of spruce for cellulosic ethanol production'. Bioreource Technology, 101,3106-3114.

[109] Tian S, Luo XL, Yang XS, Zhu JY (2010). Robust cellulosic ethanol production from SPORL-pretreated lodgepole pine using an adapted strain Saccharomyces cerevisiae without detoxification'. Bioresour Technol, 101:8678-8685.

[110] Zhu JY, Pan XJ (2010). Woody biomass pretreatment for cellulosic ethanol production: technology and energy consumption evaluation'. Bioresour Technol, 101:4992-5002.

[111] Yang Q and Pan X, "Pretreatment of Agave americana stalk for enzymatic saccharification, Bioresource Technology, vol. 126, pp. 336-340, 2012.

[112] Silva GPD, Mack M, and Contiero J, "Glycerol: a promising and abundant carbon source for industrial microbiology,Biotechnology Advances, vol. 27, no. 1, pp. 30-39, 2009.

[113] Guragain YN, Coninck JD, Husson F, Durand A, and Rakshit SK, “Comparison of some new pretreatment methods for second generation bioethanol production from wheat straw and water hyacinth, Bioresource Technology, vol. 102, no. 6, pp. 4416-4424, 2011. 
[114] Ungurean M, Fit F, ig au, C. Paul C, Ursoiu A, and Peter F, “Ionic liquid pretreatment and enzymatic hydrolysis of wood biomass, World Academy of Science, Engineering and Technology, vol. 76, pp. 387-391, 2011.

[115] Chandra, R.; Bura, R.; Mabee, W.; Berlin, A.; Pan, X.; Saddler, J. Substrate pretreatment: The key to effective enzymatic hydrolysis of lignocellulosics? Adv. Biochem. Eng. Biotechnol. 2007, 108, 67-93.

[116] McMillan, J. D. Himmel, M. E., Baker, J. O., Overend, R. P., Eds.; Pretreatment of lignocellulosic biomass. In Enzymatic ConVersion of Biomass for Fuels Production; American Chemical Society: Washington, DC, 1994; pp 292-324.

[117] Grous, W. R.; Converse, A. O.; Grethlein, H. E. Effect of steam explosion pretreatment on pore size and enzymatic hydrolysis of poplar. Enzyme Microb. Technol. 1986, 8, 274-280.

[118] Ruiz, E.; Cara, C.; Manzanares, P.; Ballesteros, M.; Castro, E. Evaluation of steam explosion pretreatment for enzymatic hydrolysis of sunflower stalks. Enzyme Microb. Tech. 2008, 42, 160-166.

[119] Ballesteros, M.; Oliva, J.M.; Negro, M.J.; Manzanares, P.; Ballesteros, I. Ethanol from lignocellulosic materials by a simultaneous saccharification and fermentation process (SFS) with Kluyveromyces marxianus CECT 10875. Process Biochem. 2004, 39, 1843-1848.

[120] Morjanoff PJ, Gray PP. (1987). Optimization of steam explosion as method for increasing susceptibility of sugarcane bagasse to enzymatic saccharification'. Biotechnol Bioeng, 29, 733-741.

[121] Soderstrom J, Mats Galbe, Guido Zacchi (2005). Separate versus simultaneous saccharification and fermentation of two-step steam pretreated softwood for ethanol production'. J.Wood Chem. Technol, 25,187-202.

[122] Eklund, R.; Galbe, M.; Zacchi, G. The influence of SO2 and H2SO4 impregnation of willow prior to steam pretreatment. Bioresource Technol. 1995, 52, 225-229.

[123] Alizadeh H,Teymouri F, Gilbert TI, Dale BE. Pretreatment of switchgrass by ammonia fiber explosion (AFEX). Appl Biochem Biotechnol 2005; 124:1133-41.

[124] Balan V, Bals B, Chundawat SP, Marshall D, Dale BE.(2009). Lignocellulosic biomass pretreatment using AFEX'. Methods Mol Biol, 581,61-77.

[125] Lau MW, Gunawan C, Dale BE. (2009). The impacts of pretreatment on the fermentability of pretreated lignocellulosic biomass: a comparative evaluation between ammonia fiber expansion and dilute acid pretreatment ${ }^{\star}$. Biotechnol Biofuels, 2,30.

[126] Lau MW, Dale BE. (2010). Effect of primary degradation-reaction products from ammonia fiber expansion (AFEX) -treated corn stover on the growth and fermentation of Escherichia coli KO11‘. Bioresour Technol, 101,7849-7855.

[127] Gollapalli LE, et al.(2002). Predicting digestibility of ammonia fiber explosion (AFEX) treated straw'. Appl. Biochem. Biotechnol, 98-100, 23-35

[128] Varga E, Szengyel Z, Réczey K(2002). Chemical pretreatments of corn stover for enhancing enzymatic digestibility“. Appl. Biochem. Biotechnol, 98-100-73-87.

[129] G.P. Van Walsum et al., Conversion of lignocellulosics pretreated with liquid hot water to ethanol, Appl. Biochem. Biotechnol. 57-58 (1996) 157-170.

[130] S.P. Chundawat, B. Venkatesh, B.E. Dale, Effect of particle size based separation of milled corn stover on AFEX pretreatment and enzymatic digestibility, Biotechnol. Bioeng. 96 (2007) 219-231.

[131] Eggeman, T.; Elander, R.T. Process and economic analysis of pretreatment technologies. Bioresource Technol. 2005, 96, 2019-2025. 
[132] B. Yang, C.E. Wyman, Pretreatment: the key to unlocking low-cost cellulosic ethanol, Biofuels, Bioproducts and Biorefining. 2(1) (2008) 26-40.

[133] H. Wu et al., Facile pretreatment of lignocellulosic biomass at high loadings in room temperature ionic liquids, Biotechnology and Bioengineering. 108(12) (2011) 2865-2875.

[134] T.V. Doherty et al., Ionic liquid solvent properties as predictors of lignocellulose pretreatment efficacy, Green Chemistry. 12(11) (2010) 1967-1975.

[135] R. Arora et al., Monitoring and analyzing process streams towards understanding ionic liquid pretreatment of switchgrass (Panicum virgatum L.), Bioenergy Research. 3(2) (2010) 134145.

[136] G. Papa et al., Exploring the effect of different plant lignin content and composition on ionic liquid pretreatment efficiency and enzymatic saccharification of Eucalyptus globulus L. mutants, Bioresource Technology. 117 (2012) 352-359.

[137] D. Yuan et al., Aviable method and configuration for fermenting biomass sugars to ethanol using native Saccharomyces cerevisiae, Bioresource Technology. 117 (2012) 92-98.

[138] Lee JW, Gwak KS, Park JY, et al. (2007). Biological pretreatment of softwood pinus densiflora by three white rot fungi‘. J. Microbiol, 45,485-491.

[139] Qiu Z, Aita GM, and Walker MS, Effect of ionic liquid pretreatment on the chemical composition, structure and enzymatic hydrolysis of energy cane bagasse, Bioresource Technology, vol. 117, pp. 251-256, 2012.

[140] Perez-Pimienta JA, Lopez-Ortega MG, Varanasi P, Vitalie S, Gang C, Seema S, Blake AS, Comparison of the impact of ionic liquid pretreatment on recalcitrance of agave bagasse and switchgrass, Bioresource Technology, vol. 127, pp. 18-24, 2013.

[141] Muhammad N, Man Z, Bustam MA, Mutalib MIA, Wilfred CD, and Rafiq S, “Dissolution and delignification of bamboo biomass using amino acid-based ionic liquid, Applied Biochemistry and Biotechnology, vol. 165, no. 3-4, pp. 998-1009, 2011.

[142] Zhi-Guo Z and Hong-Zhang C, Enhancement of the enzymatic hydrolysis of wheat straw by pretreatment with 1-allyl- 3-methylimidazolium chloride $([\mathrm{Amim}] \mathrm{Cl})$ African Journal of Biotechnology, vol. 11, no. 31, pp. 8032-8037, 2012.

[143] Hou XD, Smith TJ, Li N, Zong MH (2012) Novel renewable ionic liquids as highly effective solvents for pretreatment of rice straw biomass by selective removal of lignin. Biotechnol Bioeng 109:2484-2493 doi: 10.1002/bit.24522

[144] Ninomiya K, Yamauchi T, Kobayashi M, Chiaki O, Nobuaki , Kenji T, "Cholinium carboxylate ionic liquids for pretreatment of lignocellulosic materials to enhance subsequent enzymatic saccharification,Biochemical Engineering Journal, vol. 71, pp. 25-29, 2013.

[145] Wang X, Li H, Cao Y, Tang Q (2011). Cellulose extraction from wood chip in an ionic liquid 1-allyl-3-methylimidazolium chloride (AmimCl). Bioresour Technol, 102: 7959-7965.

[146] Brandt A, Ray MJ, To TQ, Leak DJ, Murphy RJ, Welton T (2011). Ionic liquid pretreatment of lignocellulosic biomass with ionic liquid-water mixtures.Green Chemistry, 13:2489-2499.

[147] Sun N, Rahman M, Qin Y, Maxim ML, Rodríguez H, Rogers RD (2009). Complete dissolution and partial delignification of wood in the ionic liquid 1-ethyl- 3methylimidazolium acetate. Green Chemistry , 11: 646-655

[148] Shamsuri AA, Abdullah DK (2010). Isolation and characterization of lignin from rubber wood in ionic liquid medium. Modern Applied Sci, 4: 19- 27.

[149] Lynam JG, Toufiq Reza M, Vasquez VR, Coronella CJ (2012). Pretreatment of rice hulls by ionic liquid dissolution. Bioresour Technol , 114: 629 - 636. 
[150] Dibble DC, Li C, Sun L, George A, Cheng A, Çetinkol ÖP, Benke P, Holmes BM, Singh S, Simmons BA (2011). A facile method for the recovery of ionic liquid and lignin from biomass pretreatment. Green Chemistry 2011, 13: 3255 -3264.

[151] Garc'1a-Cubero MT, Gonz'alez-Benito G, Indacoechea I, Coca M, and Bolado S, Effect of ozonolysis pretreatment on enzymatic digestibility of wheat and rye straw, Bioresource Technology, vol. 100, no. 4, pp. 1608-1613, 2009.

[152] Sannigrahi P, Hu F, Pu Y, and Ragauskasa A, Novel oxidative pretreatment of Loblolly Pine, Sweetgum, and Miscanthus by ozone, Journal of Wood Chemistry and Technology, vol. 32, pp. 361-375, 2012.

[153] Schultz-Jensen N, K'ad'ar Z, Thomsen AB, Bindslev H, and Leipold F, Plasma-assisted pretreatment of wheat straw for ethanol production, Applied Biochemistry and Biotechnology, vol. 165, no. 3-4, pp. 1010-1023, 2011.

[154] Travaini R, Otero MD, Coca M, Da-Silva R, and Bolado S, “Sugarcane bagasse ozonolysis pretreatment: effect on enzymatic digestibility and inhibitory compound formation, Bioresource Technology, vol. 133, pp. 332-339, 2013.

[155] C.K. Nitsos et al., Optimization of Hydrothermal Pretreatment of Lignocellulosic Biomass in the Bioethanol Production, Process Chem. Sus. Chem. 6 (2013) 110-122.

[156] Muhammad Saif Ur Rehman, Ilgook Kim, Yusuf Chisti, Jong-In Han. Use of ultrasound in the production of bioethanol from lignocellulosic biomass (2013) Energy Education Science and Technology Part A: Energy Science and Research, 30(2), 1391-1410.

[157] L'opez-Linares JC, Romero I, Moya M, Cara C, Ruiz E, Castro E, Pretreatment of olive tree biomass with $\mathrm{FeCl} 3$ prior enzymatic hydrolysis, Bioresource Technology, vol. 128, pp. 180$187,2013$.

[158] H. Li, J. Xu, Optimization of microwave-assisted calcium chloride pretreatment of corn stover, Bioresource Technology. 127 (2013) 112-118.

[159] Kurakake M, Ide N, Komaki T.. Biological pretreatment with two bacterial strains for enzymatic hydrolysis of office paper, Curr. Microbiol. 54 (2007) 424-428.

[160] Yengkhom Disco Singh, Pinakeswar Mahanta, Utpal Bora (2017) Comprehensive characterization of lignocellulosic biomass through proximate, ultimate and compositional analysis for bioenergy production, Renewable Energy 103 (2017) 490-500

[161] Schurz J. Bioconversion of Cellulosic Substances into Energy Chemicals and Microbial Protein Symp. Proc.; Ghose, T. K.; Ed.; New Delhi, IIT: Delhi, 1978; pp. 37.

[162] Ander P, Eriksson K.-E. Lignin degradation and utilization by microorganisms. In: Bull M J (Ed.), editor. Progress in Industrial Microbiology. Amsterdam: Vol. 14, Elsevier, 1978; pp.1-58.

[163] Hwang S S, Lee S J, Kim H K, Ka JO, Kim KJ, Song HG. Biodegradation and saccharification of wood chips of Pinus strobus and Liriodendron tulipifera by white rot fungi. J Microbiol Biotechnol, 2008; 18: 1819-1825.

[164] F.A. Keller, J.E. Hamilton, Q.A. Nguyen, Microbial pretreatment of biomass-potential for reducing severity of thermochemical biomass pretreatment, Appl. Biochem. Biotechnol. 105 (2003) $27-41$.

[165] Zhang XY, Yu HB, Huang HY, et al. Evaluation of biological pretreatment with white rot fungi for the enzymatic hydrolysis of bamboo culms. Int Biodeterior Biodegrad, 2007; 60: $159-164$.

[166] C.C. Geddes et al., Optimizing the saccharification of cane bagasse using dilute phosphoric acid followed by sugar fungal cellulose, Bioresour. Technol. 101 (2010) 1851-1857. 
[167] I. Romero et al., Ethanolic fermentation of phosphoric acid hydrolysates from olive tree pruning, Ind. Crop Prod, 25 (2007) 160-168.

[168] I.U. Nieves et al., Injection of air into the headspace improves fermentation of phosphoric acid pretreated sugarcane bagasse by Escherichia coli MM170, Bioresour Technol. (2011) doi:10.1016/j.biortech.2011.04.036.

[169] Gauss WF, Suzuki S, Takagi M .(1976). Manufacture of alcohol from cellulosic materials using plural ferments'. U.S. Patent No. 3990944.

[170] Huff GF, Yata N.(1976). Enzymatic hydrolysis of cellulose‘. U.S. Patent No.3990945.

[171] Neves MA, Shimizu N, Kimura T, Shiiba K. (2007). Kinetics of bioethanol production from wheat milling by-products‘. Journal of Food Process Engineering, in press.

[172] Geddes CC, Mullinnix MT, Nieves IU, Peterson JJ, Hoffman RW, York SW, Yomano LP, Miller EN, Shanmugam KT, Ingram LO. (2011). Simplified process for ethanol production from sugarcane bagasse using hydrolysate-resistant Escherichia coli strain MM160'. Bioresour Technol, 102, 2702-2711.

[173] Zhou SD, Ingram LO. (2001). Simultaneous saccharification and fermentation of amorphous cellulose to ethanol by recombinant Klebsiella oxytoca SZ21 without supplemental cellulase'. Biotechnol Lett, 23, 1455-1462.

[174]C.E. Wyman et al., Comparative sugar recovery and fermentation data following pretreatment of poplar wood by leading technologies'. Biotechnol prog, 25 (2009) 333-339.

[175] Wen F, Sun J, Zhao H., Yeast surface display of trifunctional minicellulosomes for simultaneous saccharification and fermentation of cellulose to ethanol, Appl. Environ. Microbiol. 76 (2010) 1251-1260.

[176] S. Morais et al., Cellulase-xylanase synergy in designer cellulosomes for enhanced degradation of a complex cellulosic substrate, mBio, 1 (2010) e00285-00210.

[177] J.B. Kristensen, C. Felby, H. Jorgensen, Yield-determining factors in high- solids enzymatic hydrolysis of lignocellulose, Biotechnol Biofuels. 2 (2009) 11.

[178] K. Karolina et al., Key issues in modeling and optimization of lignocellulosic biomass fermentative conversion to gaseous biofuels. Renewable Energy 129 (2018) 384-408.

[179] B. Chiara et al., Influence of feedstock, catalyst, pyrolysis and hydrotreatment temperature on the composition of upgraded oils from intermediate pyrolysis. Biomass and Bioenergy 116 (2018) 236-248

[180]K. Pasi et al., Fine grinding of wood - Overview from wood breakage to applications. Biomass and Bioenergy 113 (2018) 31-44 